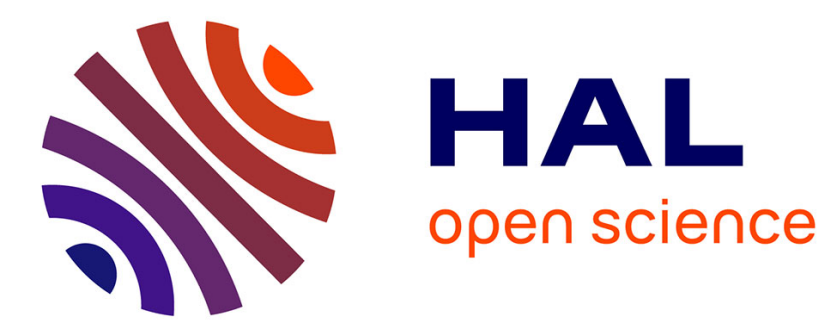

\title{
The Phospha-Michael Addition in Organic Synthesis
}

Dieter Enders, Alexandre Saint-Dizier, Marie-Isabelle Lannou, Achim Lenzen

\section{To cite this version:}

Dieter Enders, Alexandre Saint-Dizier, Marie-Isabelle Lannou, Achim Lenzen. The Phospha-Michael Addition in Organic Synthesis. European Journal of Organic Chemistry, 2006, 2006 (1), pp.29-49. 10.1002/ejoc.200500593 . hal-02371130

\section{HAL Id: hal-02371130 https://hal.science/hal-02371130}

Submitted on 13 Oct 2021

HAL is a multi-disciplinary open access archive for the deposit and dissemination of scientific research documents, whether they are published or not. The documents may come from teaching and research institutions in France or abroad, or from public or private research centers.
L'archive ouverte pluridisciplinaire HAL, est destinée au dépôt et à la diffusion de documents scientifiques de niveau recherche, publiés ou non, émanant des établissements d'enseignement et de recherche français ou étrangers, des laboratoires publics ou privés. 


\title{
The Phospha-Michael Addition in Organic Synthesis
}

\author{
Dieter Enders, ${ }^{*[a]}$ Alexandre Saint-Dizier, ${ }^{[a]}$ Marie-Isabelle Lannou, ${ }^{[a]}$ and Achim Lenzen ${ }^{[a]}$
}

Keywords: Michael addition / Conjugate addition / Phosphorus / Asymmetric synthesis

Phosphorus is essential for many reagents in organic synthesis, for ligands of late-transition metals and for phosphonoand phosphanylamino acids, the latter being important isosteres of amino acids. Similar to the Michaelis-Arbuzov and the Michaelis-Becker reaction the phospha-Michael addition, i.e. the addition of a phosphorus nucleophile to an acceptor-substituted alkene or alkyne, certainly represents one of the most versatile and powerful tools for the formation of $\mathrm{P}-\mathrm{C}$ bonds since many different electrophiles and $\mathrm{P}$ nu- cleophiles can be combined with each other. This offers the possibility to access many diversely functionalised products. With this article, we try to give an instructive overview of this reaction. The outline of this review is supposed to be rather general and it is its goal to make the reader familiar with reactivity principles which are common to the different classes of electrophiles and/or P nucleophiles.

\section{Introduction}

Without any doubt, since the early work by Wittig, phosphorus compounds have emerged to be tremendously important for many different areas in chemistry and especially in organic synthesis. In this regard, phosphorus is not only essential for various reagents, among which different types of ylides and phosphonates ("Wittig" and "Horner-Wadsworth-Emmons" reagents, respectively) are probably the most prominent, but also important as donor atom in many structurally and electronically diverse ligands for late-transition metals. Moreover, molecules incorporating a phosphonic $\left[\mathrm{P}(\mathrm{O})(\mathrm{OH})_{2}\right]$, a phosphinic $[\mathrm{P}(\mathrm{O})(\mathrm{OH}) \mathrm{R}]$ or a phosphonate $\left[\mathrm{P}(\mathrm{O})(\mathrm{OR})_{2}\right]$ group and an amino group can be regarded as isosteres of amino acids. As such or as part of pseudopeptides, they can act as substrate mimics and interfere with enzymatic processes. ${ }^{[1]}$

In addition, natural products containing a $\mathrm{P}-\mathrm{C}$ bond mostly exhibit important biological activities. ${ }^{[2]}$

Apart from the well-known Michaelis-Arbuzov and Michaelis-Becker reaction (reaction of trialkyl phosphites with alkyl halides and of alkali salts of dialkyl phosphonates with alkyl halides, respectively), the phospha-Michael ( $P$ Michael) addition is probably one of the most important tools for $\mathrm{P}-\mathrm{C}$ bond formation. Since the early report by

[a] Institut für Organische Chemie, RWTH Aachen,

Landoltweg 1, 52074 Aachen, Germany

Fax: +49-241-809 2127

E-mail: enders@rwth-aachen.de
Pudovik, ${ }^{[3]}$ however, reviews on this subject have been scarce and have dealt mostly with rather special aspects like metal-catalysed reactions ${ }^{[4]}$ or phosphorus radicals. ${ }^{[5]}$ This more general review is intended to fill this gap.

It is needless to say that a vast number of publications deal with this topic - being comprehensive is therefore far beyond the scope of this review. Because one publication generally deals with different kinds of electrophiles and/or $\mathrm{P}$ nucleophiles, the organisation of this article appeared problematic at first glance since disturbing overlaps seemed to be unavoidable. However, we do hope to have overcome this problem and presented a readable account. It appeared most appropriate to us to make a rough division according to the nature of the acceptor compound. Only in the first chapter about carbonyl/carboxyl compounds, a further subdivision with regard to the $\mathrm{P}$ nucleophile seemed to be advisable.

\section{Olefinic Acceptors Bearing Carbonyl or Carboxyl Groups (or Derivatives Thereof)}

\section{$\mathrm{Ph}_{3} \mathrm{P}$ as Nucleophile}

The Michael addition of a trivalent phosphorus nucleophile to an olefinic acceptor first formally results in the formation of a phosphobetaine. The stability of this betain determines whether the desired addition is successful or not. Galkin and co-workers ${ }^{[6]}$ for example studied the reaction 
of triphenylphosphane with acrylic acid (1) (Scheme 1). ${ }^{[7]}$ They were able to isolate the betain $\mathbf{3}$ in high yield, which had obviously been formed from the initial species 2 by a proton-transfer reaction. The structure of $\mathbf{3}$ could also be proven by X-ray analysis, and it was shown that betains like 3 unavoidably incorporate molecules in the solid state which are capable of forming hydrogen bonds.

The reactions with cinnamic acid (4) and $p$-methoxycinnamic acid (5) proceeded in the same way. Yet, in this case, an equilibrium between the betains $\mathbf{6}$ and 7 and their corresponding phosphoranes $\mathbf{8}$ and $\mathbf{9}$ was observed. The formation of the latter was attributed to the fact that substituents at phosphorane rings generally tend to stabilize them.

Interestingly, with butyl methacrylate (10) only (anionic) polymerisation was observed. This does not only show that the initially formed $P$-Michael adduct was highly reactive but also that the polymerisation was faster than the addition reaction itself.

It is quite obvious that side reactions such as the one just described can be circumvented if one is able to trap the initially formed betain. This is done most easily with a proton source. Cristau and co-workers ${ }^{[8]}$ reported on $P$ Michael additions of triphenylphosphane to the $\alpha, \beta$-unsaturated ketones 11a-e in the presence of $\mathrm{HBr}$ (Scheme 2). ${ }^{[9]}$ The phosphonium salts 12a-e were obtained in good to very good yields.

In order to use these salts in subsequent reactions the carbonyl groups were protected to give the phosphonium salt acetals 13a,c-e and the phosphonium salt thioacetals 14a-e. Later, it was shown by the same authors that the phosphonium salt thioacetals $\mathbf{1 4 a - e}$ could be easily deprotonated with $t \mathrm{BuOK}$ to give the corresponding ylides. The latter could be used successfully in alkylation, acylation and Wittig reactions. ${ }^{[10]}$ Note, that Umpolung is involved in these reactions because these ylides represent homoenolate equivalents in these reactions.

Alternatively, Ohmori and co-workers ${ }^{[1]}$ have shown that lutidinium salts can also be employed instead of $\mathrm{HBr}-$ conditions obviously being much milder in the light of the significant lower acid strength of the former. However, a pro-

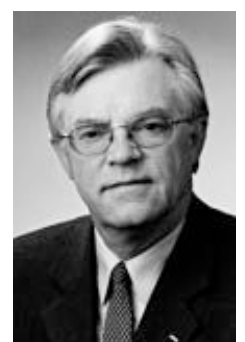

Dieter Enders was born in 1946 in Butzbach, Germany. He studied chemistry at the Justus Liebig University of Giessen and received his Dr. rer. nat. in 1974 under the supervision of Prof. Dieter Seebach. After postdoctoral studies at Harvard University with Prof. E. J. Corey, he returned to Giessen and obtained his habilitation in 1979. In 1980 he moved to the University of Bonn as an associate professor before he changed again in 1985 to his present position as Professor of Organic Chemistry at the Rheinisch-Westfälische Technische Hochschule Aachen. He received many awards, among them the Prize of the Justus Liebig University of Giessen (1978), the Leibniz Award (Deutsche Forschungsgemeinschaft, 1993), the Yamada Prize (Japan, 1995), the Max-Planck Research Award (Alexander von Humboldt-Stiftung and MaxPlanck-Gesellschaft, 2000) and the Emil Fischer Medal (Gesellschaft Deutscher Chemiker, 2002). His current research interests are asymmetric synthesis, especially the synthesis of biologically active compounds, asymmetric catalysis with nucleophilic carbenes and new synthetic methods using organometallics and organocatalysis in general.

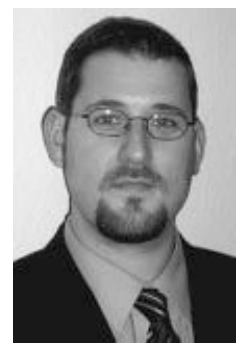

Alexandre Saint-Dizier was born in 1975 in France. He studied chemical engineering in Nancy (France) before moving to England where he received a B.Sc. (Hon) in Chemistry from Kingston University (1998). He then joined the group of Professor J. D. Kilburn at the University of Southampton (UK) and obtained his Ph. D. in organic chemistry in the field of radical cyclisations in 2002. After spending 18 months in industry, as a synthetic chemist with CSS, in Northern Ireland, he moved to the RWTH Aachen (Germany) joining the group of Prof. D. Enders for a post-doctoral stay. His work focused on asymmetric synthesis using the SAMP/RAMP methodology. Alexandre is now working as a process development chemist with Syngenta in Monthey (Switzerland).

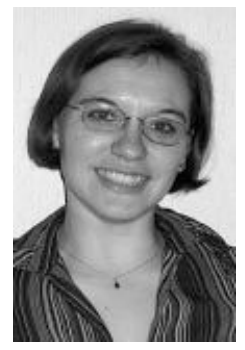

Marie-Isabelle Lannou, born in 1975 in Villeneuve Saint Georges (France), studied chemistry at the University of Paris $X I$ (Orsay) and obtained her Master degree as an Erasmus student at the University of Kent at Canterbury. She received her Ph. D. in 2002 from the University of Paris XI (Orsay) and then joined Prof. Enders'group at the RWTH Aachen as a post doctoral fellow, where she worked on the asymmetric synthesis of natural products. Since September 2004, she occupies a contractual position as assistant professor (ATER) at the University of Cergy-Pontoise where she works under the supervision of Prof. J. Ardisson and Dr. A. Pancrazi on the total synthesis of antitumoural agents.

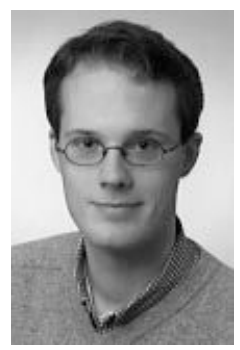

Achim Lenzen, born 1977 in Geilenkirchen (Germany), studied chemistry at the RWTH Aachen and the University of Toronto. He obtained his Dr. rer. nat. in 2005 under the guidance of Prof. D. Enders completing the total syntheses of attenol $A$ and B, (+)-strictifolion and the 1-epi-aglycon of the cripowellins. Since August 2005 he is working as a post doctoral fellow in the group of Prof. $K$. C. Nicolaou at the Scripps Research Institute in La Jolla, California (Feodor Lynen fellowship). 

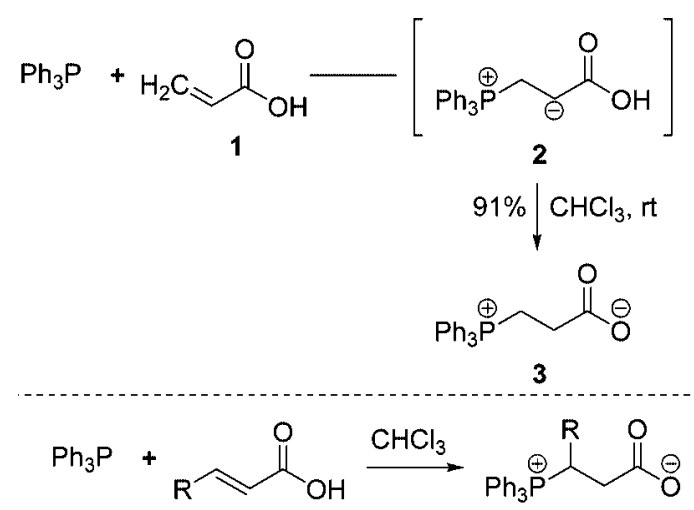

4: $\mathrm{R}=\mathrm{Ph} \quad 6: \mathrm{R}=\mathrm{Ph}$

5: $\mathrm{R}=\mathrm{pMeOPh} \quad$ 7: $\mathrm{R}=p \mathrm{MeOPh}$

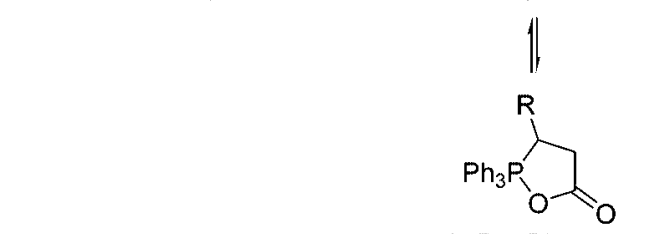

8: $\mathrm{R}=\mathrm{Ph}$

9: $\mathbf{R}=p \mathrm{MeOPh}$

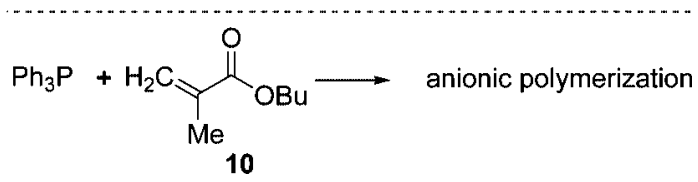

Scheme 1.

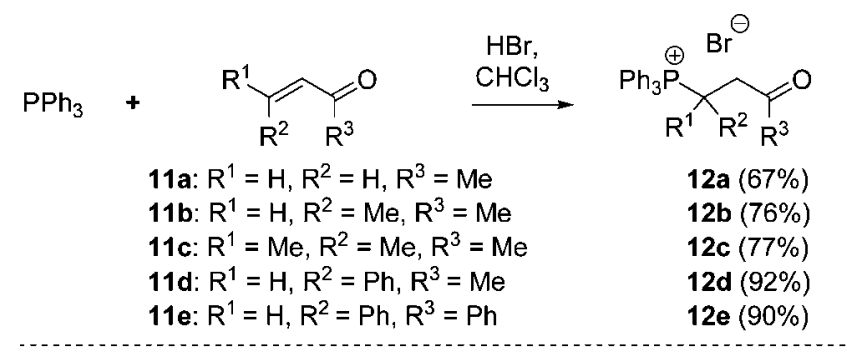

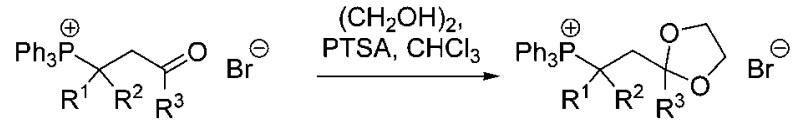

$$
\begin{aligned}
& \text { 12a,c-e 13a (47\%) } \\
& 13 \mathrm{c}(25 \%) \\
& 13 \mathrm{~d}(73 \%) \\
& 13 \text { e }(52 \%)
\end{aligned}
$$

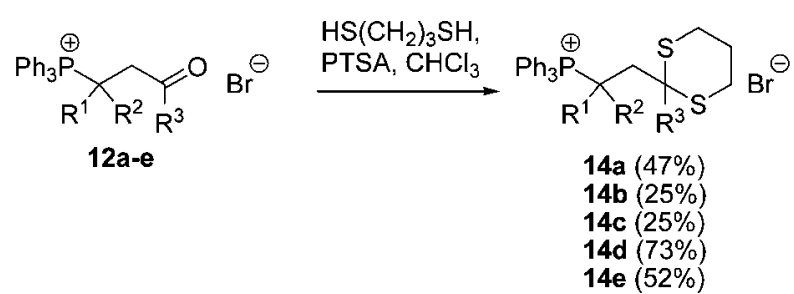

Scheme 2.

ton is not the only possibility to trap an intermediate betain. This can also be accomplished using " $\mathrm{Si}^{+}$" - either in form of silyl chlorides as described by Evans and co- workers $^{[12]}$ or in form of silyl triflates. An interesting application of the latter is the method described by Kozikowski and Jung (Scheme 3). ${ }^{[13,14]}$

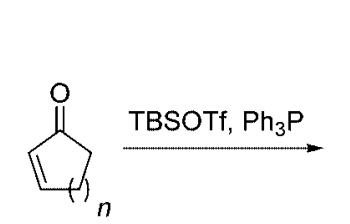

15: $n=1$
16: $n=2$

17: $n=3$

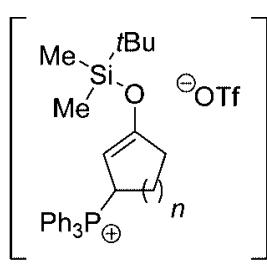

18: $n=1$

19: $n=2$

20: $n=3$

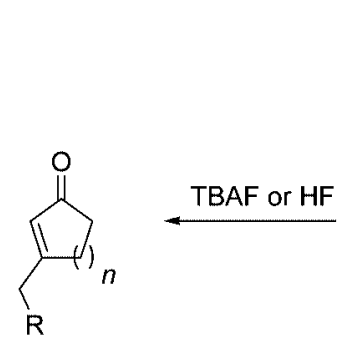

24a $(68 \%)$

24b $(63 \%)$

$24 \mathrm{c}(69 \%)$

25 a $(80 \%)$

25b $(77 \%)$

25c $(82 \%)$

25d $(51 \%)$

26a $(82 \%)$

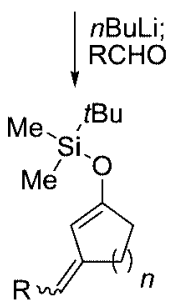

$$
\begin{aligned}
& \text { 21a: } n=1, \mathrm{R}=\operatorname{PPr}(81 \%) \\
& \text { 21b: } n=1, \mathrm{R}=\operatorname{Ph}(75 \%) \\
& \text { 21c: } n=1, \mathrm{R}=n \operatorname{Pent}{ }^{*} \\
& \text { 22a: } n=2, \mathrm{R}=\operatorname{Pr}(86 \%) \\
& \text { 22b: } n=2, \mathrm{R}=\operatorname{Ph}(83 \%) \\
& \text { 22c: } n=2, \mathrm{R}=n \operatorname{Pent}^{*} \\
& \text { 22d: } n=2, \mathrm{R}=\operatorname{crotyl}^{*}(74 \%) \\
& \text { 23a: } n=3, \mathrm{R}=n \operatorname{Pr}^{\star} \\
& \text { * yield not determined }
\end{aligned}
$$

Scheme 3.

Using the cyclic enones 15-17 a sequence of Michael addition (giving 18-20) and Wittig olefination could be carried out in one pot furnishing the unsaturated silyl enol ethers 21a-c, 22a-d and 23a in good yields. The following desilylation restored the original double bond to give the substituted analogues 24a-c, 25a-d and 26a.

Using acrolein as the carbonyl compound, Kozikowski obtained a mixture of the $E$-silyl enol ether and the 1,2addition product (1.8:1). Under the same conditions, however, the aldehyde 27 yielded only the 1,4-addition product 28 (Scheme 4). This was used in the development of a new benzannulation sequence: After a Wittig reaction, the diene 29 was reacted with dimethyl acetylenedicarboxylate (30) in a Diels-Alder cycloaddition to yield 31. Acid-induced elimination then furnished the benzene derivative $\mathbf{3 2}$.

A conceptually similar approach was developed by Kim and Lee. ${ }^{[15]}$ Instead of simply exposing the ylides $\mathbf{3 3}$ and $\mathbf{3 4}$ to aldehydes (cf. Scheme 4), they added TMSOTf at the same time which resulted in an effective trapping of the intermediate betains (Scheme 5). TBAF-mediated desilylation led to an elimination of triphenylphosphane and furnished the $\beta$-hydroxylated enones 35a-c and 36a,b.

Apart from aldehydes, Michael acceptors were also shown to be applicable. The same procedure delivered the $\beta$-substituted enones 37a,b and 38a-e. Only one example of an acyclic enone (4-hexen-3-one) was presented although 


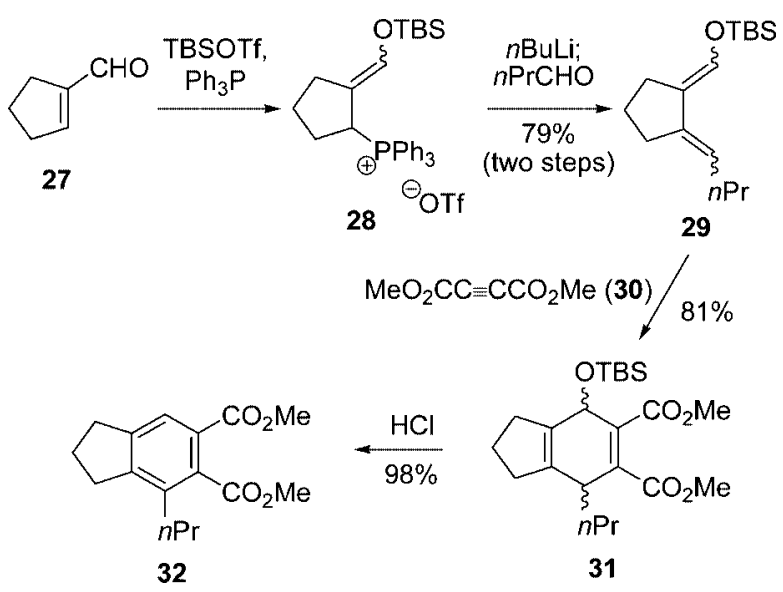

Scheme 4

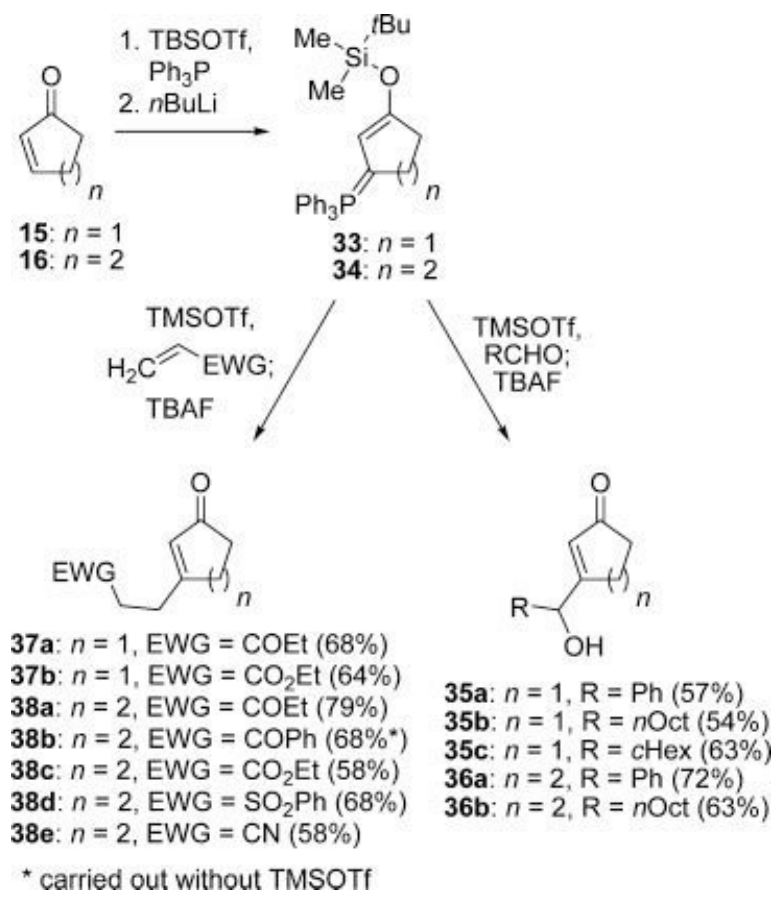

Scheme 5 .

the yields obtained were comparable and even superior in some cases.

So far, the discussion has focused on $\mathrm{Ph}_{3} \mathrm{P}$ as the $\mathrm{P}$ nucleophile, and it should have become clear that the common feature of all methodologies presented was the generation of ylides, which in turn allowed some kind of coupling reactions. These were always accompanied by the loss of either $\mathrm{Ph}_{3} \mathrm{P}$ or $\mathrm{Ph}_{3} \mathrm{PO}$.

It is needless to say that the vast majority of $P$-Michael additions focuses on exactly the opposite, i. e. the introduction of one or more phosphorus atoms with the aim to preserve the $\mathrm{P}-\mathrm{C}$ bond formed. One just needs to visualize the enormous number of phosphorus ligands and bioactive phosphonic and phosphinic acids that are formed this way.
Considering these other classes of $\mathrm{P}$ nucleophiles, those with a $\mathrm{P}(\mathrm{O})-\mathrm{H}$, a $\mathrm{P}-\mathrm{OR}$ bond [capable of undergoing an Arbuzov-type rearrangement after the $P$-Michael addition to give the corresponding $\mathrm{P}(\mathrm{O})$ compound] or those with a $\mathrm{P}-\mathrm{H}$ bond (phosphanes or phosphane--boranes) are probably more important.

\section{Nucleophiles of the General Structure $\mathrm{P}(\mathrm{O}) \mathrm{H}$ or $\mathrm{P}(\mathrm{S}) \mathrm{H}$}

With regard to nucleophiles of the general structures $\mathrm{R}_{2} \mathrm{P}(\mathrm{O}) \mathrm{H}$ or $\mathrm{R}_{2} \mathrm{P}(\mathrm{S}) \mathrm{H}$ (with $\mathrm{R}=$ alkyl, aryl, alkoxy) different investigations ${ }^{[16]}$ have been carried out focusing on the issue of 1,2- vs. 1,4-addition to unsaturated carbonyl compounds. Although each combination of acceptor and nucleophile has to be considered separately, generalisations can be made, which are most easily exemplified with the addition of dibutylphosphane oxide (39) to mesityl oxide (40) (Scheme 6). ${ }^{[17]}$

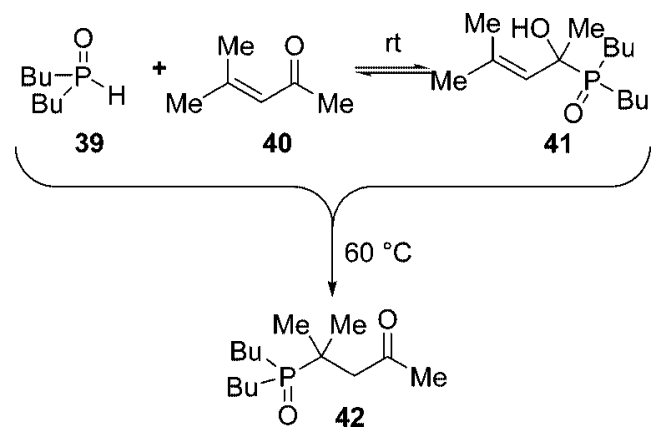

Scheme 6.

At room temperature the 1,2-addition product $\mathbf{4 1}$ is slowly formed. Heating the mixture to $60^{\circ} \mathrm{C}$ leads to the exclusive formation of the 1,4-addition product $\mathbf{4 2}$. From these facts one has to conclude that: a) $\mathbf{4 2}$ is thermodynamically more stable than $\mathbf{4 1}$ (which could also have been anticipated without any doubt due to the conservation of the $\mathrm{C}=\mathrm{O}$ bond) and b) $\mathbf{4 1}$ arises from a kinetic reaction control; its formation is reversible since $\mathbf{4 2}$ is formed also at the expense of $\mathbf{4 1}$.

Unlike in the preceding example, the Michael addition of a $\mathrm{R}_{2} \mathrm{P}(\mathrm{O}) \mathrm{H}$ group is normally conducted under basic conditions - either in the presence of a basic catalyst (e. g. $\mathrm{K}_{2} \mathrm{CO}_{3}{ }^{[18]}$ alkaline alkoxides in alcoholic solutions, ${ }^{[19]}$ $\mathrm{DBU}^{[20]}$ ) or by using a strong base (e. g. NaH, $n \mathrm{BuLi}$, $\left.\mathrm{Et}_{2} \mathrm{Zn}\right)$ in stoichiometric amount. ${ }^{[21]}$

In this regard, tetramethylguanidine (TMG, 43) seems to offer some operational advantages because this catalyst is commercially available and seems to be widely applicable (Scheme 7). ${ }^{[22]}$ Under the standard reaction conditions (diethyl phosphite as the $\mathrm{P}$ nucleophile and reaction solvent, $0{ }^{\circ} \mathrm{C}$ or room temp., short reaction time) methyl vinyl ketone (44) furnished the 1,2 adduct, whereas $\mathbf{4 6}$ underwent the Michael addition exclusively. $\alpha, \beta$-Unsaturated esters like 48a,b and nitriles like 49 can also be used to give the addition products $\mathbf{5 0 a}, \mathbf{b}$ and $\mathbf{5 1}$ in moderate yields. 


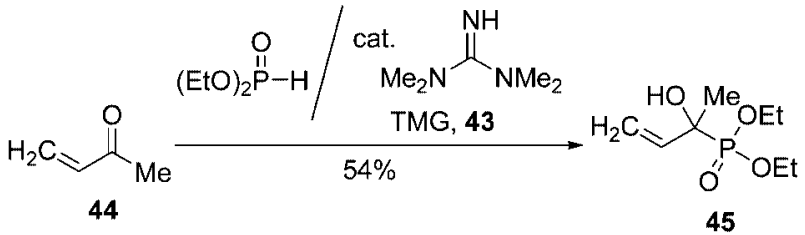<smiles></smiles>

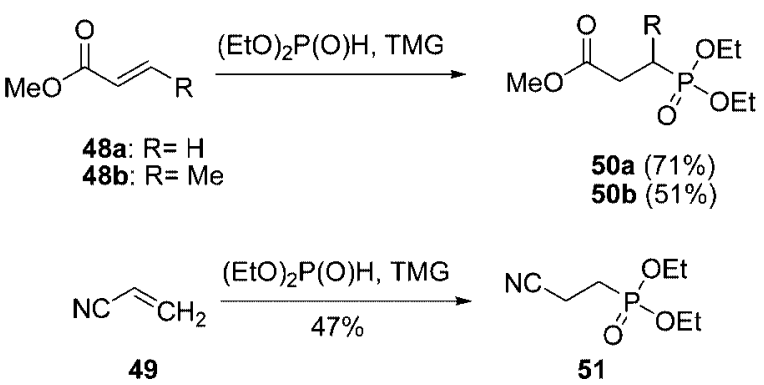

Scheme 7.

An interesting alternative to the base-catalysed addition of $\mathrm{P}(\mathrm{O}) \mathrm{H}$ groups to Michael acceptors is the analogous microwave-assisted conversion under "neat conditions" (i.e. without any solvent or catalyst).[23]

In 1976, Burgada and co-workers studied the addition of cyclic phosphoranes bearing a $\mathrm{P}-\mathrm{H}$ bond to alkenes. ${ }^{[24]} \mathrm{A}$ few years later, this study was extended to a comparison of phosphoranes and phosphites. Although both nucleophiles seemed to be very similar to each other - both featuring only one $\mathrm{P}-\mathrm{H}$ bond and a phosphorus atom in the oxidation state +IV - they behaved strikingly differently (Scheme 8). ${ }^{[25]}$
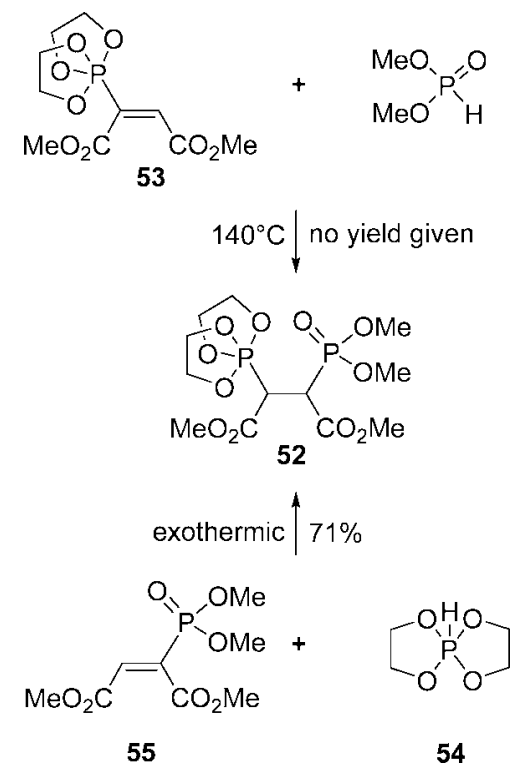

Scheme 8.
The diester $\mathbf{5 2}$ was prepared by two different pathways. Whereas the addition of dimethyl phosphite to the acceptor 53 was a sluggish process requiring heating at $140{ }^{\circ} \mathrm{C}$, the addition of phosphorane $\mathbf{5 4}$ to the olefin $\mathbf{5 5}$ represented an exothermic process. In the latter case, it was envisaged that penta- or hexacoordinate intermediates, analogues to those observed in phosphate chemistry, could have been involved. The reader should realise that this study was not suitable for figuring out the origin of the difference in reactivity. It might have been based upon the nucleophile, the electrophile or even both. However, it is clear that the coordination sphere of phosphorus has a pronounced effect on reactivity.

The Michael addition of $\mathrm{P}(\mathrm{O}) \mathrm{H}$ groups has also been conducted stereoselectively - both with chiral $\mathrm{P}$ nucleophiles and with chiral Michael acceptors. Haynes, Yeung and co-workers ${ }^{[26]}$ for example used lithiated tert-butyl(phenyl)phosphane oxide (56) in additions to saturated and unsaturated carbonyl compounds (Scheme 9).
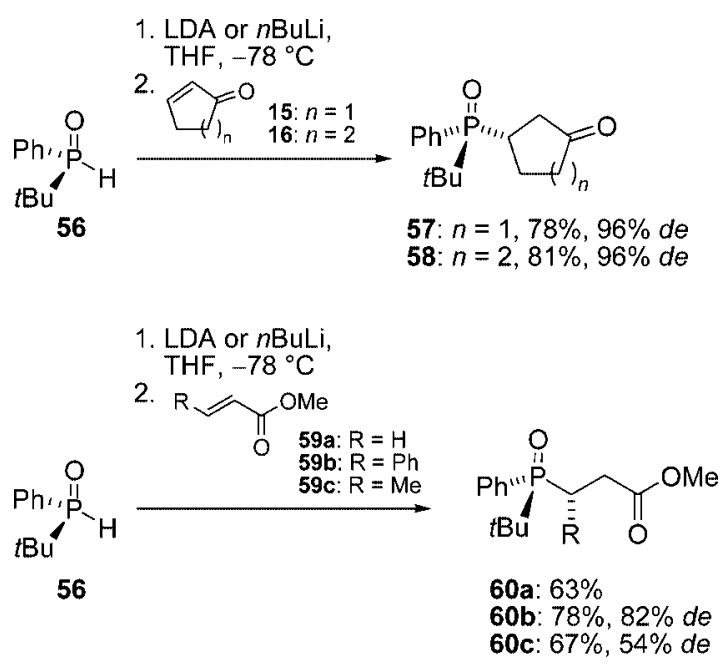

Scheme 9.

Whereas unsaturated aldehydes exclusively underwent 1,2-addition, the cyclic enones $\mathbf{1 5}$ and $\mathbf{1 6}$ and the unsaturated esters $\mathbf{5 9} \mathbf{a}-\mathbf{c}$ yielded the 1,4-addition products $\mathbf{5 7}, \mathbf{5 8}$ and $60 \mathrm{a}-\mathbf{c}$, respectively, and with moderate to excellent diastereoselectivity. It should be noted that this sequence proceeded with retention of configuration at the phosphorus atom.

Our group employed the TADDOL-derived chiral phosphite 61 (for its synthesis, see Scheme 41) in additions to the aromatic alkylidene malonates 62 (Scheme 10). ${ }^{[27]}$

The reactions were carried out under heterogeneous conditions using $\mathrm{KOH}$ as base on $\mathrm{Fe}_{2} \mathrm{O}_{3}$ as solid support. The phosphonates 63 were obtained in moderate to good yields and with very good diastereoselectivities. The auxiliary was then cleaved using TMSCl/NaI leaving behind the corresponding silyl esters. Their hydrolysis simply involved exposure to $\mathrm{H}_{2} \mathrm{O}$ giving compounds 64 . Due to their very high polarity they were first converted into their respective methyl esters in order to facilitate their analysis on a chiral stationary phase. This revealed that the cleavage of the aux- 


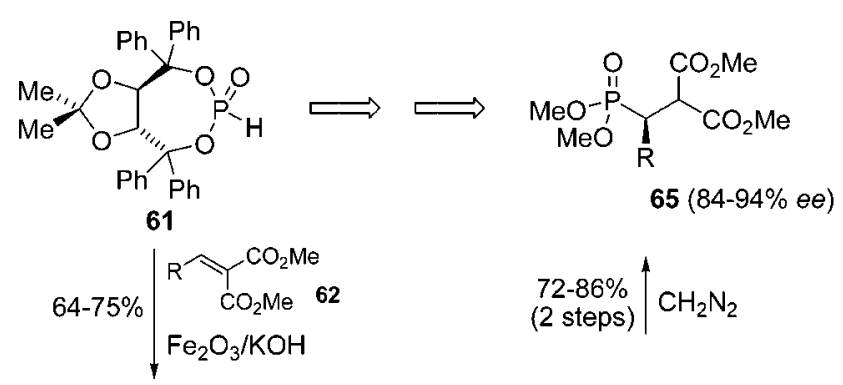<smiles>[R]C(C(=O)OP1(=O)OC(c2ccccc2)(c2ccccc2)C2OC(C)(C)OC2C(c2ccccc2)(c2ccccc2)O1)C(C(=O)OC)C(=O)OC</smiles><smiles>[R]=Cc1ccc([Al])cc1</smiles>

Scheme 10 .

iliary had proceeded without any detectable epimerisation or racemisation.

Although alkyl-substituted alkylidene malonates behaved similarly well with regard to yield, the diastereoselectivities were only meagre.

During their extensive study of the nucleophilic addition of dialkyl phosphites to unsaturated amides, imides and oxazolines, Quirion and co-workers ${ }^{[2]}$ identified $\beta$-amino alcohols as the most effective chiral auxiliaries. As indicated in the upper half of Scheme 11, this reaction was thoroughly optimised with regard to the nucleophile, the electrophile (i.e. $\mathrm{R}^{1}$ to $\mathrm{R}^{6}$ ) and the base.

The system that ensured the highest diastereoselectivities is shown in the bottom half. After formation of the sodium salt of diethyl phosphite, addition to the unsaturated amides $69 \mathbf{a}-\mathbf{d}$ gave rise to the formation of the respective 1,4-addition products $\mathbf{7 0 a}-\mathbf{d}$ in moderate yields. The diastereoselectivity was excellent in cases where the substituent
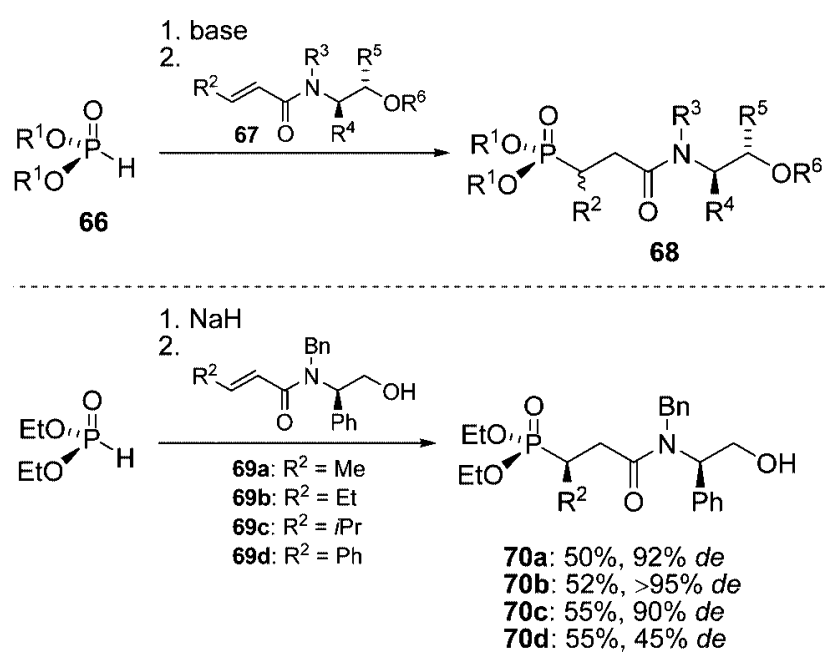

Scheme 11

of the acrylic amide moiety was aliphatic (70a-c, $>90 \%$ $d e$, but dropped significantly in the case of aromatic substituents (70d, $45 \%$ de). The final removal of the chiral auxiliary was accomplished using $8 \mathrm{M} \mathrm{HCl}$.

\section{Nucleophiles of the General Structure $\mathbf{R}_{2} \mathbf{P}\left(O R^{\prime}\right), \operatorname{RP}\left(O R^{\prime}\right)_{2}$ and $\left(\mathbf{R}^{\prime} \mathbf{O}\right)_{3} \mathbf{P}$}

Another interesting class of nucleophiles are trivalent phosphorus compounds of the general structure $\mathrm{R}_{2} \mathrm{P}\left(\mathrm{OR}^{\prime}\right)$, $\mathrm{RP}\left(\mathrm{OR}^{\prime}\right)_{2},\left(\mathrm{R}^{\prime} \mathrm{O}\right)_{3} \mathrm{P}$. Like in the case of triphenylphosphane the addition (formally) also proceeds via a betain intermediate. In this case, however, four different reaction pathways are accessible in principle. Which of them is being followed strongly depends on the reaction conditions and the particular substrates.

The study conducted by Dvořák and co-workers ${ }^{[29]}$ helps to illustrate this (Scheme 12). Reaction of the (arylmethylene)malonaldehydes $\mathbf{7 1}$ with trimethyl phosphite gave the methoxyacroleins $\mathbf{7 3}$ in moderate to good yields. ${ }^{[30]}$ This re-
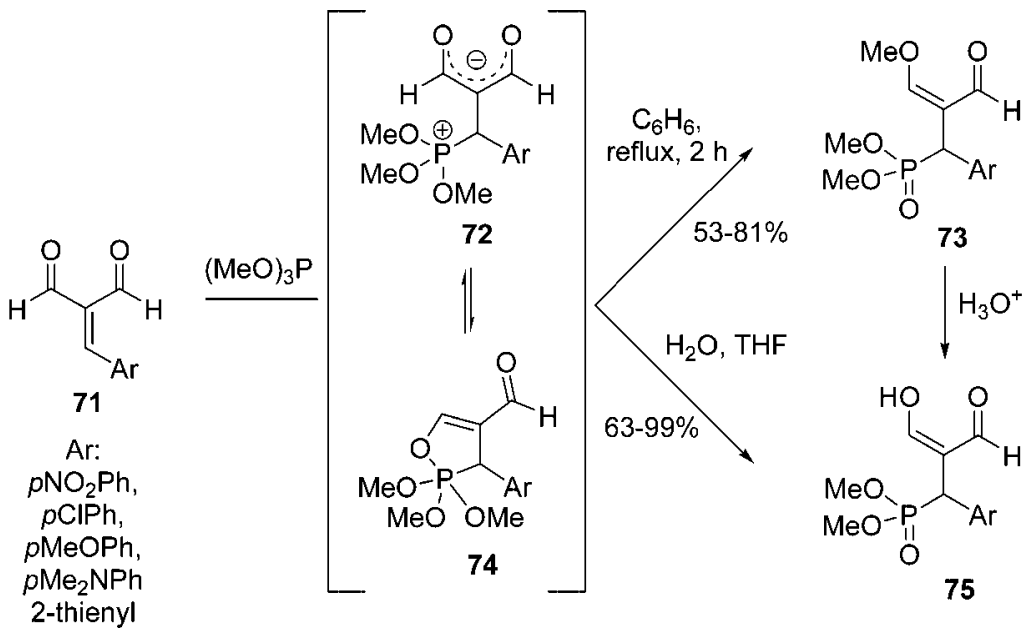

Scheme 12. 
action can be envisaged to proceed via an Arbuzov-type rearrangement (intra- or intermolecularly) of the intermediate betain 72. This first pathway obviously corresponds to an $O$-alkylation of the enolate 72. A $C$-alkylation is also possible, but it is not observed in this case and also less common (second pathway). ${ }^{[31]}$

Under certain conditions (temperature, substitution type of the phosphorus atom) ${ }^{[32]}$ the betain exists in equilibrium with the corresponding phosphorane $74 .{ }^{[33]}$ In the case of $\mathrm{Ar}=p-\mathrm{ClC}_{6} \mathrm{H}_{4}$, this phosphorane could even be isolated and characterised (third pathway). In the presence of a proton source, like $\mathrm{H}_{2} \mathrm{O}$ in this case, the phosphonium structure $(\mathrm{RO})_{3} \mathrm{P}^{+}$- rearranges without a transfer of $\mathrm{R}$ to the anionic centre of the betain to give the corresponding (RO) ${ }_{2} \mathrm{P}(\mathrm{O})$ compound $\mathbf{7 5}$ (fourth pathway). The methoxyacroleins $\mathbf{7 3}$ could be hydrolysed under acid catalysis to give $\mathbf{7 5}$. Performing the Michael addition in alcoholic solvents can also lead to the (intermolecular) formation of phosphoranes (Scheme 13). ${ }^{[34]}$<smiles>C=CC(=O)OCC</smiles>

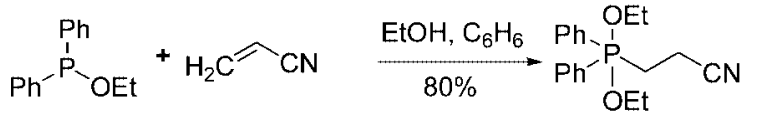<smiles>C=CC(=O)OCC</smiles>

Scheme 13.

Strictly speaking, the Arbuzov rearrangement ${ }^{[35]}$ involves the reaction of an ester of trivalent phosphorus with alkyl halides. After $P$-alkylation, the intermediate phosphonium species rearranges to give the respective phosphonate. In contrast, the same transformation, phosphite $\rightarrow$ phosphonate, was brought about by an initial Michael addition event in the example above (Scheme 12, $71 \rightarrow 73$ ). Therefore, one might describe this as an Arbuzov-type rearrangement. Its intramolecular version was described by Janecki and Bodalski ${ }^{[36]}$ in their synthesis of 2-methoxycarbonyland 2-(cyanoallyl)phosphonates (Scheme 14).

Esterification of the Baylis-Hillman adducts 76a,b with diethyl phosphorchloridite furnished the phosphites $\mathbf{7 7 a}, \mathbf{b}$ which underwent a [2.3]-sigmatropic rearrangement to the allylphosphonates $\mathbf{7 8 a}, \mathbf{b}$ upon heating. Although both classes of phosphonates, 78a and $\mathbf{7 8 b}$, were obtained in similar yields, their $E / Z$-ratios were surprisingly different. Whereas the $Z$ isomer was formed exclusively in the case of the acrylates $\mathbf{7 8 a}$, the formation of the acrylonitriles $\mathbf{7 8 b}$ resulted in a mixture of both stereoisomers with the $E$ isomer strongly predominating.

An analogous study by Kumara Swamy and coworkers ${ }^{[37]}$ employed a cyclic phosphorchloridite instead of diethyl phosphorchloridite. However, their results parallel those that have just been described.
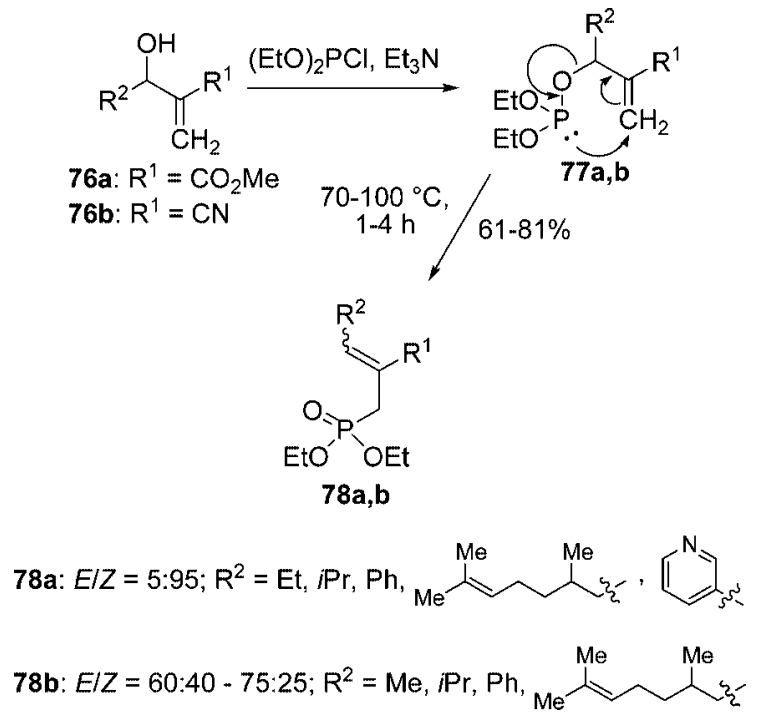

Scheme 14.

Closely related to this chemistry is the work by Basavaiah and Pandiaraju. ${ }^{[38]}$ They started from the acetylated BaylisHillman adducts 79a,b instead and performed an intermolecular $P$-Michael addition using triethyl phosphite with elimination of the acetoxy group yielding the phosphonates $\mathbf{8 0 a}, \mathbf{b}$ as mixtures of $E$ and $Z$ isomers (Scheme 15).

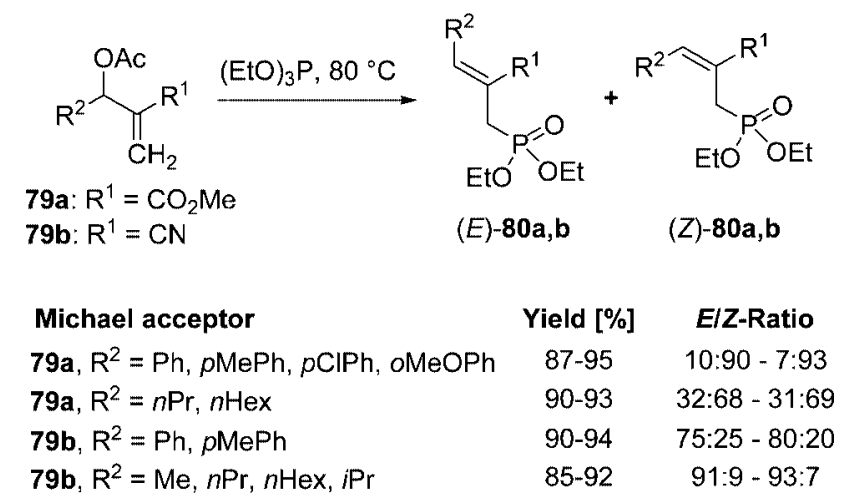

Scheme 15.

It is interesting to note that although this represents the intermolecular case, the $E: Z$-ratios parallel the ones from the intramolecular one (cf. Scheme 14): In the case of 79a, the $Z$ isomer prevails whereas the opposite is found in the case of 79b. Unlike in the intramolecular case, however, the nature of $\mathrm{R}^{2}$ also seems to play an important role. An aromatic group for example gives better selectivities for the former and worse selectivities for the latter.

Allylic halides, whose double bonds are activated towards a $P$-Michael addition, can not only undergo the 1,4-addition but also an $\mathrm{S}_{\mathrm{N}} 2$ reaction. It appears that "mono"-activated alkenes are preferentially attacked by a nucleophilic substitution whereas geminal "double"-activated olefins rather react through a $P$-Michael addition pathway. ${ }^{[39]}$

In accordance to this generalisation, Stevens and coworkers showed, that compounds incorporating both a ge- 
minal double-activated alkene and an allylic halide functionality, react with trialkyl phosphites to give cyclopropanes by a Michael addition- $\mathrm{S}_{\mathrm{N}} 2$ tandem reaction. ${ }^{[40]}$

The concept of betains that we have described so far, seems to be quite reasonable and helps to rationalize the different findings. Yet, the actual outcome of a reaction is sometimes difficult to predict and studying the respective literature is sometimes unavoidable.

Other intriguing examples are depicted in Scheme 16. In the light of the preceeding discussion further comments are regarded unnecessary at this point, and the reader is referred to the cited references. ${ }^{[41-43]}$

In the case of trivalent phosphorus nucleophiles of the general structure $\mathrm{R}_{2} \mathrm{POR}^{\prime}$ only those compounds in which $\mathrm{R}^{\prime}$ represents an alkyl or an aryl group have been under consideration so far. Although generally only 1,4-addition is observed with these compounds, the addition reactions are mostly sluggish at ambient temperature and do often require extensive heating. In this regard the corresponding silyl compounds $\left(\mathrm{R}^{\prime}=\mathrm{SiR}_{3}\right)$ represent an attractive alternative since they often allow to perform the addition reactions under much milder conditions. However, different from their alkyl/aryl counterparts, 1,2-addition is a side reaction which is sometimes observed.

Evans and co-workers ${ }^{[12]}$ studied the behaviour of various dialkyl (trialkylsilyl)phosphites $(\mathrm{RO})_{2} \mathrm{POSiR}_{3}\left(\mathrm{R}, \mathrm{R}^{\prime}=\right.$ $\mathrm{Me}, \mathrm{Me} ; \mathrm{Me}, \mathrm{Et}$; Et, Me; Et, Et) and of $\left(\mathrm{Et}_{2} \mathrm{~N}\right)_{2} \mathrm{POSiMe}_{3}$ both with saturated and unsaturated aldehydes and ketones. The following observations were made:

a) The reagents mentioned above reacted smoothly with saturated aldehydes and ketones in an 1,2-addition reaction to give the corresponding $\alpha$-siloxyphosphonates and $\alpha$-siloxyphosphonamides, respectively. The silyl transfer was shown to proceed intramolecularly, and the order of reactivity equaled $\mathrm{RCHO}>\mathrm{ArCHO}>\mathrm{RCOR}$, allowing to react aldehydes at ambient temperature (or even under cooling) whereas ketones needed prolonged heating. Interest- ingly, $\left(\mathrm{Et}_{2} \mathrm{~N}\right)_{2} \mathrm{POSiMe}_{3}$ was much more reactive than its oxygen counterparts.

Instead of using $(\mathrm{RO})_{2} \mathrm{POSiMe}_{3}$ a mixture of $(\mathrm{RO})_{3} \mathrm{P}$ and $\mathrm{Me}_{3} \mathrm{SiCl}$ (which is operationally more simple since both are commercially available) led to the same outcome. However, from a mechanistic point of view both variants were shown to be distinctly different, since the reaction with the latter did not simply proceed via the formation of $(\mathrm{RO})_{2} \mathrm{PO}-$ $\mathrm{SiMe}_{3}$.

b) With unsaturated carbonyl compounds the same trends in reactivity were observed both with regard to the nucleophiles and the electrophiles. The mode of addition, i.e. 1,2 vs. 1,4 , seemed to be kinetically controlled and to favour the formation of the $Z$ isomer.

A distinct difference between $(\mathrm{MeO})_{2} \mathrm{POSiMe}_{3}$ and the two-reagent alternative $(\mathrm{MeO})_{3} \mathrm{P} / \mathrm{Me}_{3} \mathrm{SiCl}$ was also noticed: Whereas acrolein afforded nearly a 1:1 mixture of 1,2 and 1,4 adducts with the former only the 1,2-addition product was found with the latter. Methyl vinyl ketone on the other hand underwent 1,4-addition exclusively with all reagents.

Analogously, dialkyl (trimethylsilyl)phosphites add to acrylonitrile $^{[44]}$ and $\alpha, \beta$-unsaturated esters ${ }^{[45]}$ to give dialkyl 2cyano-2-(trimethylsilyl)ethanephosphonates and 3-alkoxy3-(trimethylsiloxy)-2-propenephosphonates (i.e. ketene silyl acetals), respectively.

A very intriguing contribution to this field was made by Mori and co-workers. ${ }^{[46]}$ They found out that the addition of dialkyl trimethylsilyl phosphites [prepared in situ from the corresponding dialkyl phosphite and $\mathrm{N}, \mathrm{O}$-bis(trimethylsilyl)acetamide (BSA)] to cyclic enones (the most difficult class of acceptors among $\alpha, \beta$-unsaturated carbonyl compounds) proceeded smoothly in the presence of a catalytic amount of TMSOTf (Scheme 17).

A variety of substrates were tested giving the desired $P$ Michael adducts 82 in good to excellent yields after acidic work-up. Mixtures of 1,4 and 1,2 adducts were isolated only in the case of cyclopentenone and 2-methylcyclohexenone.

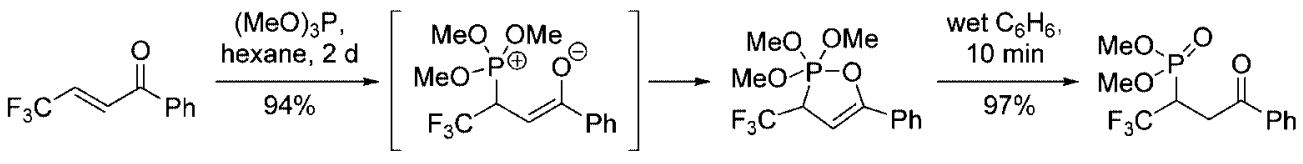

Ref. [41]<smiles>COC(=O)C1=Cc2ccccc2C(P(=O)(OC)OC)C(C(C)=O)=C1C(OC)OC(C)=O</smiles>

Ref. [42]<smiles>COP(=O)(OC)C(c1ccc(N(C)C)cc1)C(C(C)=O)C(C)=O</smiles>

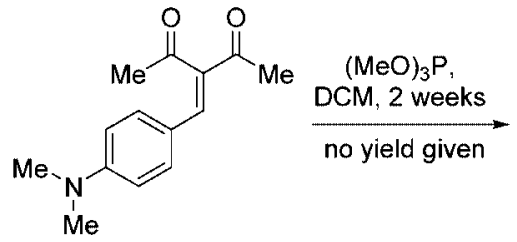<smiles>[R]C(=O)C1=C(C)OP(=O)(OC)C1c1ccc(N(C)C)cc1</smiles>

Scheme 16. 


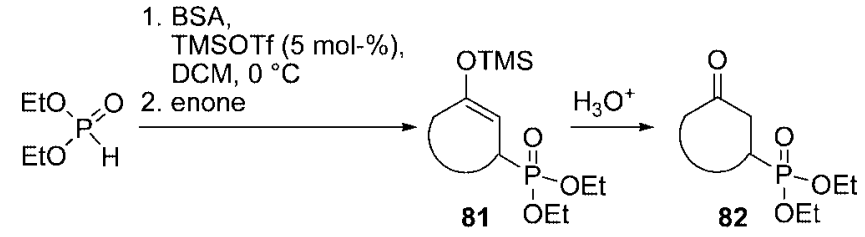

Enone, yield:

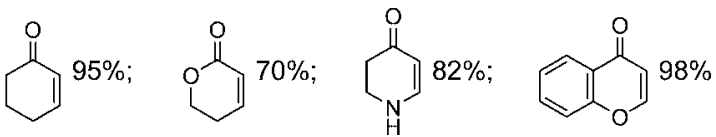

Scheme 17.

Alternatively, the same transformation can also be brought about photochemically, and a SET mechanism, in which the triplet enone accepts an electron from the silyl phosphite, has been proposed. ${ }^{[47]}$

The synthesis of phosphinic acids by a $P$-Michael addition using bis(trimethylsilyl) phosphonite (84) [BTSP, prepared in situ from ammonium phosphinate (83) with hexamethyldisilazane (HMDS)] is very much related to the chemistry just described (Scheme 18) ${ }^{[48,49]}$ Both acyclic and cyclic $\alpha, \beta$-unsaturated ketones and esters $\mathbf{8 5}$ could be reacted with this nucleophile under very mild conditions giving 86, whose acidic work-up furnished the corresponding $\gamma$-keto-substituted phosphinic acids $\mathbf{8 7}$ in good to excellent yields. For the sake of purification these acids were isolated as their adamantanamine salts. Interestingly, a second Michael addition could be conducted as well, provided that the initial addition product $\mathbf{8 6}$ was again silylated with HMDS. The double-silylated phosphonites $\mathbf{8 8}$ smoothly underwent a the second 1,4-addition to give $\mathbf{9 0}$.

Similar reaction sequences proceeding via bis(trimethylsilyl) phosphonites have also been described for the use in solid-phase organic chemistry ${ }^{[50,51]}$ and for the synthesis of $\alpha$-aminophosphinic acids. ${ }^{[52]}$

A "mixed" phosphonite, i.e. the alkyl trimethylsilyl phosphonite $\mathbf{9 2}$ has also been described and been used for various $P$-Michael additions (Scheme 19). ${ }^{[33]}$ Its synthesis was easily accomplished by silylation of the phosphonite $\mathbf{9 1}$ using hexamethyldisilazane (HMDS).

Compound 92 added readily to acetamidoacrylic acid (93) to give 94 after hydrolysis (a second equivalent of 92 was necessary for the silylation of the acrylic acid). Treatment with acid furnished the phosphonous acid 96, probably by a rearrangement as shown in $\mathbf{9 5}$. It is worth mentioning that the diethoxymethyl group can obviously be used as a protecting group for a $\mathrm{P}-\mathrm{H}$ bond.

Ebetino and co-workers ${ }^{[54]}$ have developed an asymmetric Michael addition of phosphinic and aminophosphinic acids to acrylates making use of the high reactivity of phosphorus compounds like $\mathbf{8 8}$ (cf. Scheme 18).

The (racemic) aminophosphinic acid 97a and the two

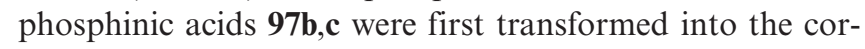
responding bis(trimethylsilyl) phosphinites 98a-c. These compounds were then reacted with the acrylimides 99a,b under very mild conditions resulting in the addition products 100a-f. These enol ethers were assumed to possess the

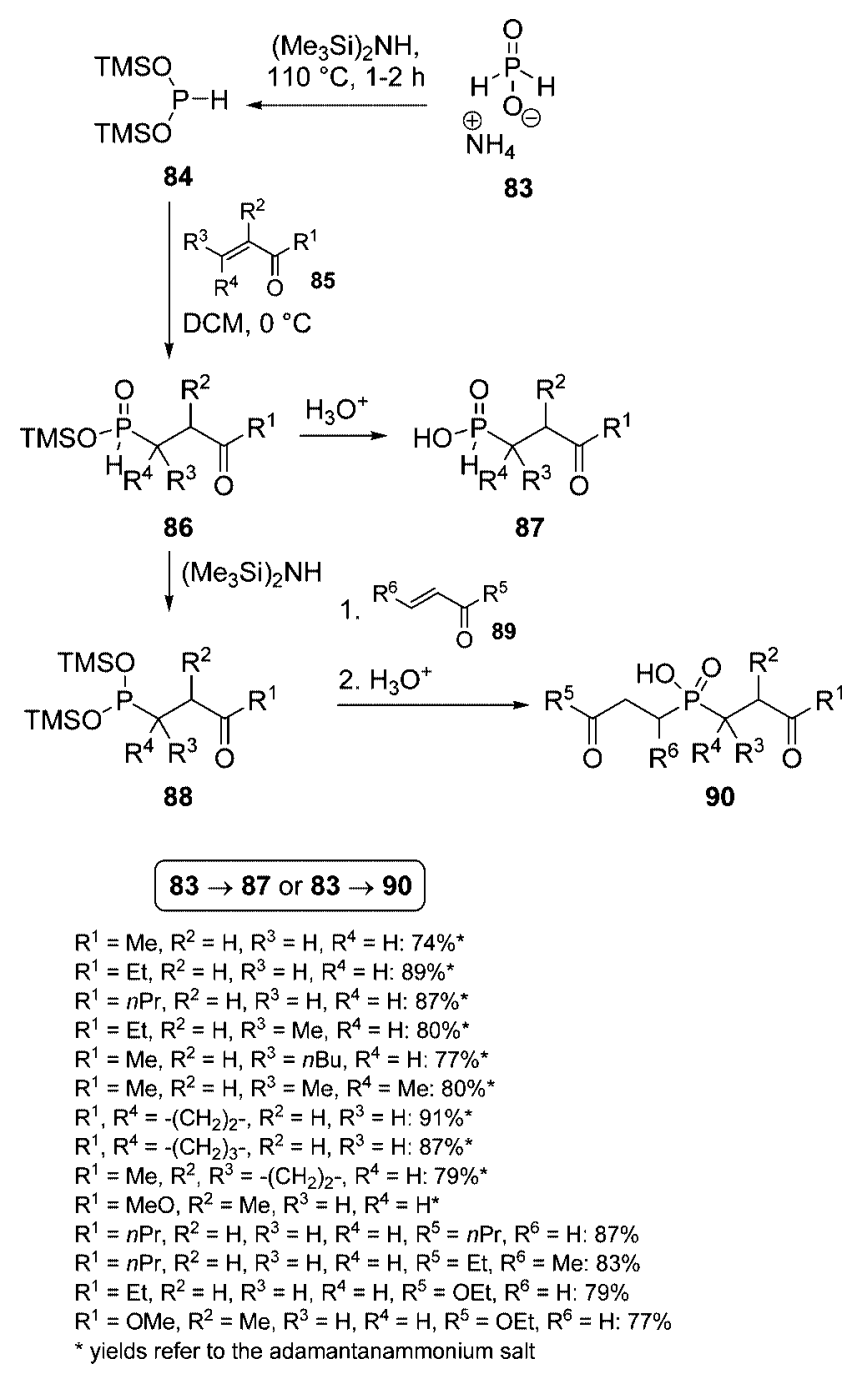

Scheme 18.
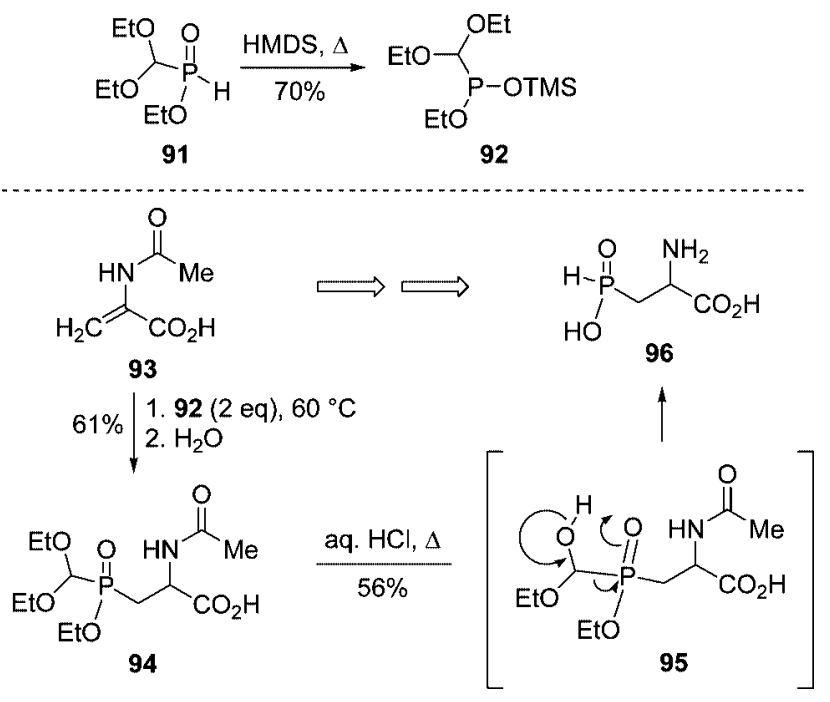

Scheme 19. 
$Z$ configuration exclusively (as depicted). A diastereoselective protonation employing EtOH finally yielded the desired products 101a-f in very good yield over two steps. In accordance with their transition-state model, the diphenylmethyl-substituted oxazolidinone 99b gave much better diastereoselectivities than its benzyl analogue 99a. The auxiliary could be cleaved successfully using $\mathrm{LiOH}$ (Scheme 20).
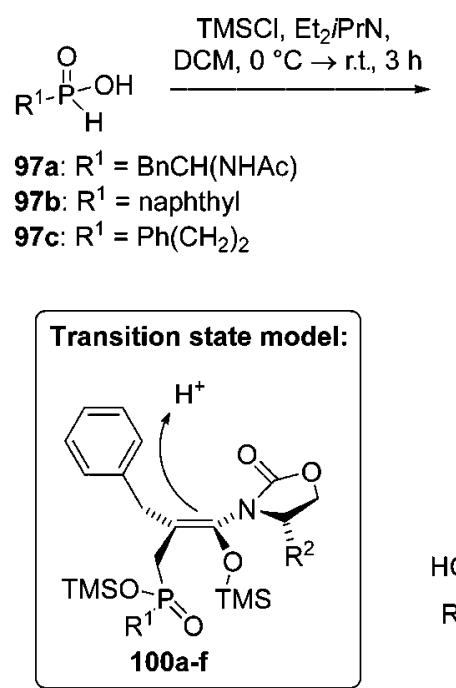<smiles>[R]P(O[Na])O[Na]</smiles>

1.

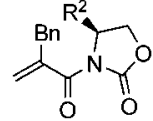
99a: $R^{2}=B n$ 99b: $\mathrm{R}^{2}=\mathrm{Ph}_{2} \mathrm{CH}$

$0{ }^{\circ} \mathrm{C} \rightarrow$ r.t. $24 \mathrm{~h}$ 2. $\mathrm{EtOH},-10{ }^{\circ} \mathrm{C}, 30 \mathrm{~min}$<smiles>[Y7]C[C@]([R8])(CP([R])(=O)O)C(=O)N1C(=O)OCC1[R]</smiles>

101a-f
RIS

3:1

$86: 1$

$5: 1$

$55: 1$

$12: 1$

$54: 1$
Scheme 20.

\section{Phosphane Nucleophiles wih $\mathbf{P}-\mathrm{H}$ Bonds}

Phosphane nucleophiles featuring one or two $\mathrm{P}-\mathrm{H}$ bonds have also been used frequently. The main purpose of these Michael additions is the synthesis of phosphane ligands for late-transition metals, since the oxidation state of phosphorus does not have to be changed afterwards anymore. Among these nucleophiles, the phenylphosphanes $\mathrm{Ph}_{2} \mathrm{PH}$ and $\mathrm{PhPH}_{2}$ are most often used - either in form of their lithium salts (vide infra) or in the presence of $\mathrm{KO} t \mathrm{Bu}^{[55]}$ as catalyst.

Helmchen and co-workers ${ }^{[56]}$ utilised $\mathrm{Ph}_{2} \mathrm{PLi}$ for the addition to (-)-(1R)-tert-butyl myrtenate (102) (Scheme 21). The reaction proceeded smoothly and diastereoselectively to give 103, which was further transformed to the actual phosphane ligand $\mathbf{1 0 5}$ in 4 steps.

This ligand was then tested in allylic substitution reactions with the cyclic substrates $\mathbf{1 0 6}$. Good to very good yields of the substitution products along with good to excellent enantioselectivities were easily achieved in the case of six- and seven-membered rings.
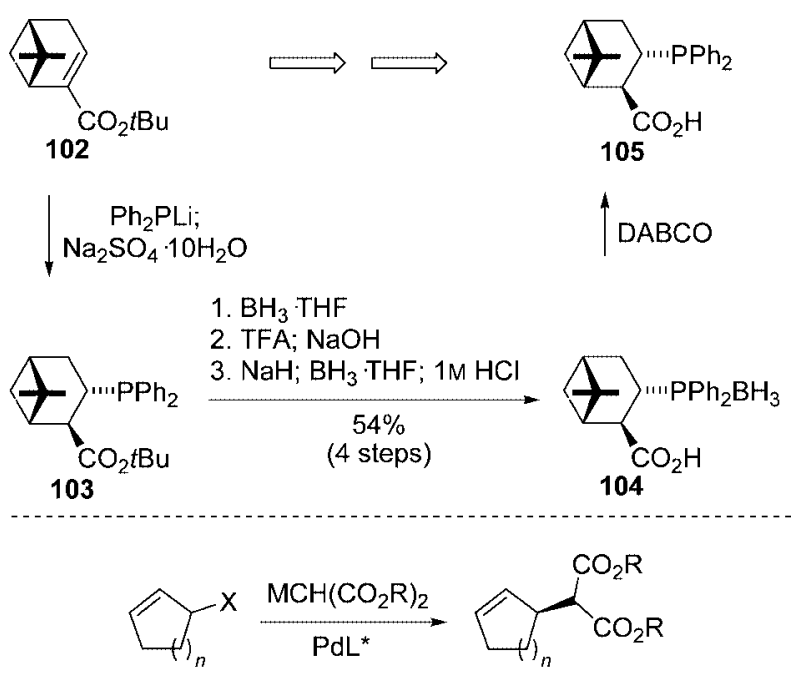

106

107

$$
n=1-3 ; \mathrm{X}=\mathrm{Cl}, \mathrm{OAc} ; \mathrm{R}=\mathrm{Me}, t \mathrm{Bu} ; \mathrm{M}=\mathrm{Li}, \mathrm{Na}
$$
yields: $73-93 \% ; 70->99 \%$ ee

Scheme 21 .

Minami and co-workers ${ }^{[57]}$ described the synthesis of enantiomerically pure 3-(diphenylphosphanyl)butanoic acid (110) (Scheme 22).

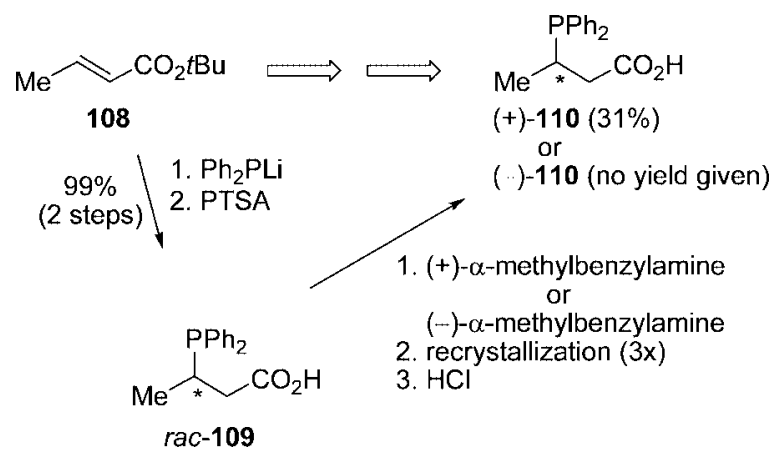

Scheme 22.

Michael addition of $\mathrm{Ph}_{2} \mathrm{PLi}$ to tert-butyl crotonate (108), followed by cleavage of the tert-butyl ester delivered the racemic acid rac-109. ${ }^{[58]}$ Both enantiomers, (+)-109 and (-)109 , could be obtained separately by repeated recrystallisation of the ammonium salt formed with (+)- $\alpha$-methylbenzylamine and (-)- $\alpha$-methylbenzylamine, respectively. The enantiomerically pure acids, whose absolute configurations were not determined, were freed by treatment with diluted hydrochloric acid and subsequently tested in asymmetric allylic alkylation reactions.

Feringa and co-workers ${ }^{[59]}$ reported on the Michael addition of $\mathrm{Ph}_{2} \mathrm{PLi}$ to $\gamma$-butenolides. Their work revealed that the reaction with methoxy-2(5H)-furanone (111) provided the lactone $\mathbf{1 1 2}$ in high yield and with high trans-diastereoselectivity (Scheme 23). 


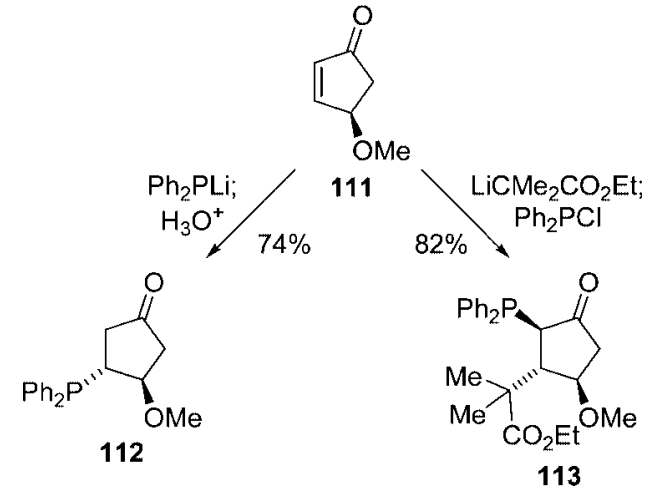

Scheme 23.

Moreover, a lactone enolate, formed after an initial Michael addition, could be trapped stereoselectively with diphenylphosphane chloride to furnish 113.

The latter tandem reaction was also used in the synthesis of the enantiomerically pure CHIRAPHOS ligand as shown in Scheme 24. Starting from 114, the lactone enolate obtained after 1,4-addition of $\mathrm{Ph}_{2} \mathrm{PLi}$ was reacted with $\mathrm{Ph}_{2} \mathrm{PCl}$ to give 115. Three further steps gave $(S, S)$-CHIRAPHOS (116) in 35\% overall yield after a specific purification step using the Bosnich method $\left(\mathrm{NiClO}_{4}\right)$.<smiles>CCOC1C=CC(=O)C1</smiles>

114

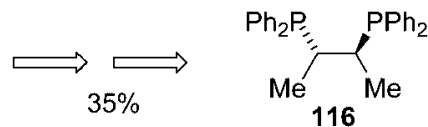

$(S, S)$-CHIRAPHOS

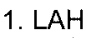

2. TsCl, pyr

3. $\mathrm{LAH}$<smiles>O=C1C[C@H](O[PbH2])[C@@H](P)[C@@H]1P</smiles>

4. purification

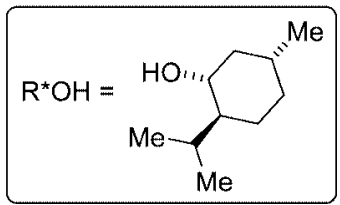

Scheme 24

Silylphosphanes ${ }^{[60]}$ generally have a much lower reactivity as compared to other metal phosphides, such as lithium phosphides. They readily react only with good electrophiles. ${ }^{[61]}$ The $P$-trimethylsilyl phospholane 118 for example, smoothly reacted with 2,3-dichloromaleic anhydride
(117) to give the bisphospholane 119, an analogue of DuPHOS (120) exhibiting a slightly larger bite angle (Scheme 25). ${ }^{[62,63]}$

Upon treatment with a fluoride source, the nucleophilicity of the phosphorus atom in silylphosphanes is enhanced dramatically. Hayashi, Watanabe and co-workers ${ }^{[64]}$ have recently shown that the combination of $\mathrm{Ph}_{2} \mathrm{PTBS}$ and TBAF in DMF is a good source for the " $\mathrm{Ph}_{2} \mathrm{P}^{-"}$ "-synthon in Michael additions to activated olefins. Scheme 26 gives some examples and it is worth mentioning that even styrenes are susceptible to this addition. ${ }^{[65]}$

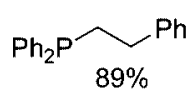<smiles>O=S(=O)(O)CCc1ccccn1</smiles><smiles>CCOC(=O)CCPc1ccccc1</smiles><smiles>CCOC(=O)CC(Pc1ccccc1)c1ccccc1</smiles>

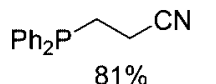<smiles>CC(=O)CCPc1ccccc1</smiles><smiles>O=C1CCCC(Pc2ccccc2)C1</smiles>

$78 \%$<smiles>C[C@H]1CCC(=O)[C@H](C(C)(C)P)C1</smiles>

Scheme 26.

The same authors were also able to extend these preliminary results to a novel three-component coupling reaction of $\mathrm{Ph}_{2} \mathrm{PTBS}$ with activated alkenes and aldehydes. The key to success in this case was to utilize $\mathrm{CsF}$ in catalytic amounts. ${ }^{[6]}$

$\mathrm{PhPH}_{2}$ has been frequently employed for the preparation of phosphorus heterocycles. In these syntheses, the phosphane undergoes two subsequent Michael additions - first inter- and then intramolecularly. An extensive conformational analysis of such heterocycles was conducted by Berlin and co-workers. ${ }^{[67]}$ They obtained these compounds by addition of $\mathrm{PhPH}_{2}$ and bis(hydroxymethyl)phosphane (124) to the $\alpha, \beta, \alpha^{\prime}, \beta^{\prime}$-unsaturated ketones $\mathbf{1 2 1}$ and $\mathbf{1 2 3}$, respectively (Scheme 27).

The desired heterocycles $\mathbf{1 2 2}$ and $\mathbf{1 2 5}$ were obtained in good yields. In addition, these products were alkylated, oxidized or sulfurized to give the corresponding phosphonium salts, phosphane oxides and phosphane sulfides - compounds that were also looked at during these studies.<smiles>C[C@H]1CC[C@@H]([13CH3])P1[13CH3]</smiles>

118
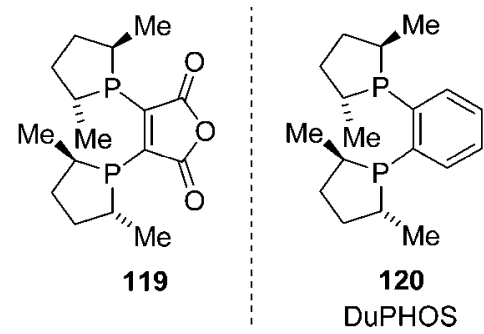


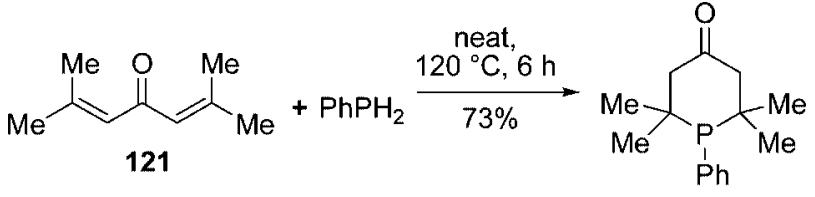

122

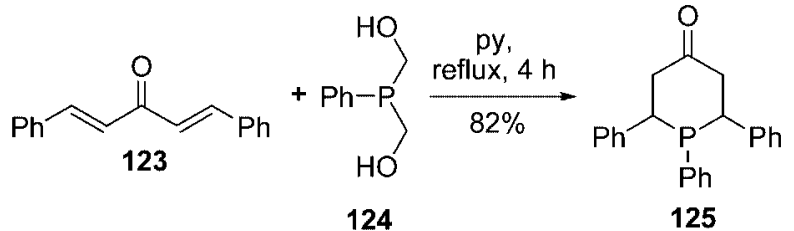

Scheme 27.

In an analogous manner, Bosyakov and co-workers synthesised the heterocycles 127a,b (Scheme 28). ${ }^{[68,69]}$
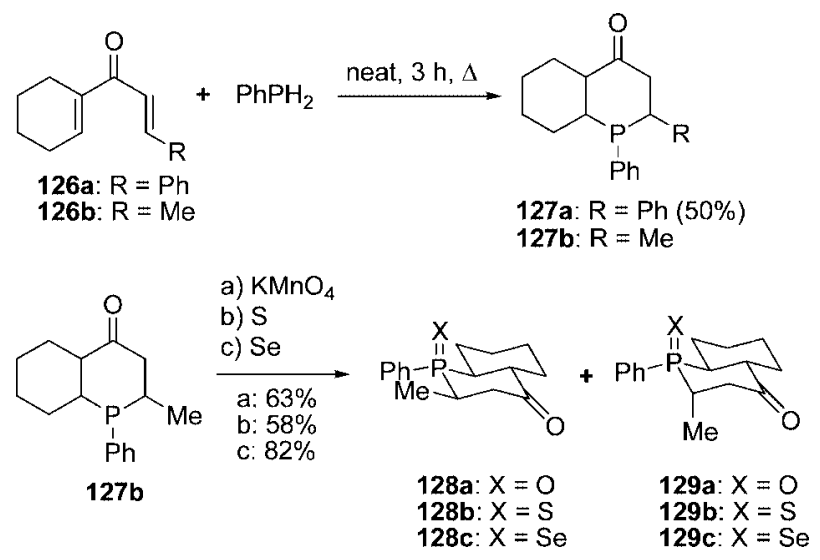

Scheme 28.

In the case of $\mathbf{1 2 7 b}$ the addition reaction was more deeply investigated. ${ }^{[68 \mathrm{~b}]}$ The crude phosphane mainly consisted of two isomers, whose ratio was shown to be dependent on the actual reaction conditions. The conversion of these two phosphane isomers into the respective phosphane oxides, sulfides or selenides did not affect their ratio, indicating the stereospecificity of these reactions. Both isomers were determined to possess the trans configuration with respect to the carbo- and the heterocycle. In the main isomer both the phenyl and the methyl group were equatorial.

\section{Phosphane-Boranes as Nucleophiles}

Phosphane-boranes are very versatile equivalents of the respective phosphanes. The borane moiety can be regarded as a protecting group, since it prevents oxidation of the phosphorus atom and its cleavage can be easily achieved in the presence of an excess of a highly nucleophilic amine (e. g. $\mathrm{Et}_{2} \mathrm{NH}$, morpholine, DABCO). They are usually prepared by the complexation of phosphanes with boranes, a method which is not always desirable because it requires handling of sometimes highly corrosive and air-sensitive phosphanes.
Imamoto and co-workers ${ }^{[70]}$ have developed an in-situ protocol for the synthesis of phosphane-boranes starting from phosphane oxides. This method was also applied to diphenylphosphane oxide (130) (Scheme 29). The resulting diphenylphosphane-borane (131) was subsequently shown to be applicable in base-catalysed Michael additions to various unsaturated acceptors 132a-f. The final tertiary phosphane-boranes 133a-f were obtained in good to very good yields. Only in the case of 133a, i.e. an unsaturated aldehyde, small amounts of 1,2-addition product were formed $(28 \%)$.

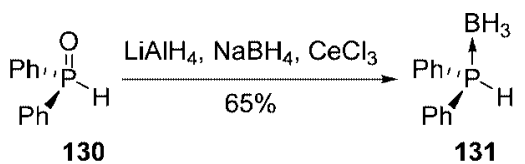

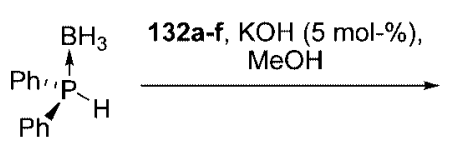

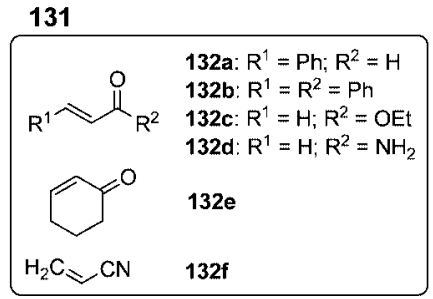

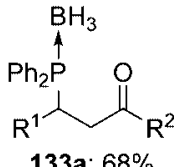

133a: $68 \%$

133b: $92 \%$

133c: $73 \%$

133d: $71 \%$

133e: $88 \%$

133f: $50 \%$
Scheme 29

Pellon and co-workers studied the addition of the same $\mathrm{P}$ nucleophile to the biselectrophile 134 (Scheme 30). Although $\mathbf{1 3 4}$ was used as a mixture of $E$ and $Z$ isomers, the addition of $\mathrm{Ph}_{2} \mathrm{P}\left(\mathrm{BH}_{3}\right) \mathrm{H}$ under catalytic conditions yielded only one diastereoisomer. ${ }^{[71 \mathrm{a}]}$
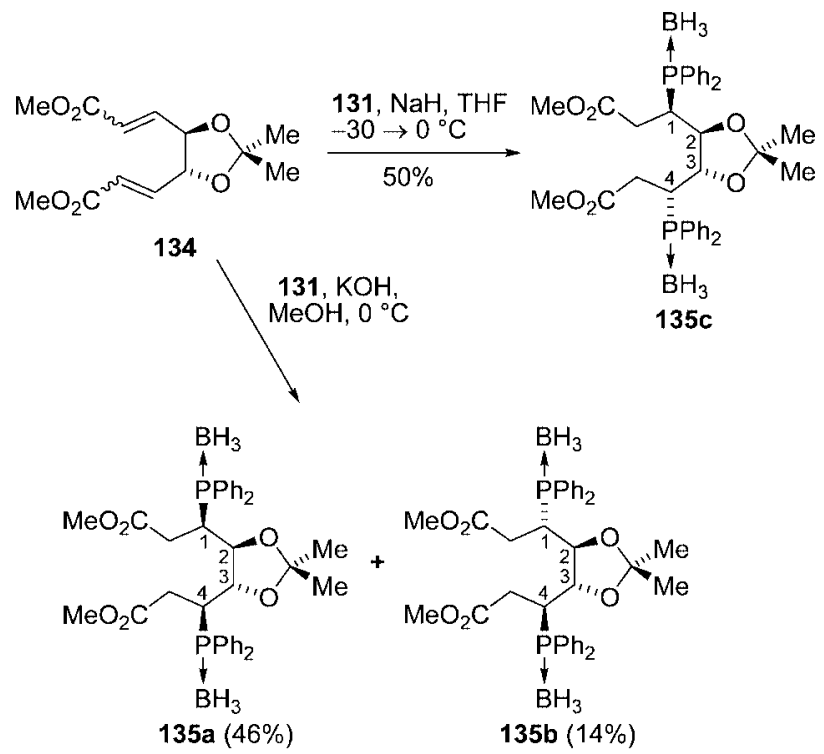

Scheme 30 .

However, the utilisation of a stoichiometric amount of the base $\mathrm{KOH}$ yielded both diastereoisomers 135a and 
135b, which could be separated by crystallisation. Isomer 135c was obtained from the reaction of $\mathrm{Ph}_{2} \mathrm{P}\left(\mathrm{BH}_{3}\right) \mathrm{Na}$ and 134 in THF.

After removal of the borane protecting groups with $\mathrm{DABCO}$, the resulting bisphosphanes were tested in Rhcatalysed asymmetric hydrogenations of $\alpha$-acetamidoacrylic acid. The ligand obtained from 135a led to better enantioselectivities than DIOP ( $80 \%$ vs. $72 \%$ ee), whereas the analogues obtained from $135 \mathbf{b}$ and 135c gave inferior enantioselectivities (69\% and $24 \%$ ee, respectively). These results show that the configurations at $\mathrm{C} 1$ and $\mathrm{C} 4$ of the phosphane ligands have a profound effect on the enantioselectivity of the reaction.

Similar to their work on dialkyl phosphites (cf. Scheme 11), Quirion and co-workers ${ }^{[72]}$ also studied the 1,4addition to unsaturated amides using $\mathrm{Ph}_{2} \mathrm{P}\left(\mathrm{BH}_{3}\right) \mathrm{Li}$. In this case, an optimisation of the reaction revealed the necessity to use a primary amine as the chiral auxiliary (as opposed to phosphites, where a secondary amine is used). Interestingly, the nucleophilic attack of lithiated $\mathbf{1 3 1}$ to the double bond now occurs from the opposite face to give the tertiary phosphane-boranes 137 a-d in moderate yields and diastereomeric excesses (Scheme 31).

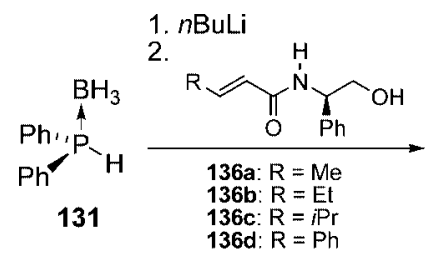<smiles>[R]C(CC(=O)NC(CO)c1ccccc1)P([B])([B])(c1ccccc1)c1ccccc1</smiles>

137a: $61 \%, 68 \%$ de 137b: $62 \%, 74 \%$ de 137c: $75 \%, 64 \%$ de 137d: $76 \%, 45 \%$ de

Scheme 31

\section{Olefinic Acceptors Bearing a Nitro Group}

In a mechanistic study Pudovik and co-workers reported the product distribution formed by the reaction between nitroalkenes and diphenyl phosphinites. ${ }^{[73]}$ The fate of the reaction intermediates and products was investigated depending on the solvent and the temperature. It became apparent that the course of the reaction was very much dictated by the actual conditions.

Vafina and co-workers ${ }^{[74]}$ investigated the Michael addition of trimethyl phosphite to $\beta$-nitrostyrene (138) (Scheme 32).

They found that the product distribution was dependent on the reaction conditions with the nitroalkylphosphonate 139 being predominant when using a solvent or an additive capable of acting as a proton source. If the reaction was carried out in ether with naphthalene as additive, the formation of 140 was favoured, whereas a mixture of 140 and 141 (3:2 ratio) was obtained in the absence of naphthalene. The reaction yielded mainly the oxime 141 if tert-butyl alcohol was used as solvent. It was also reported that compound $\mathbf{1 4 0}$ could further react with trimethyl phosphite (a

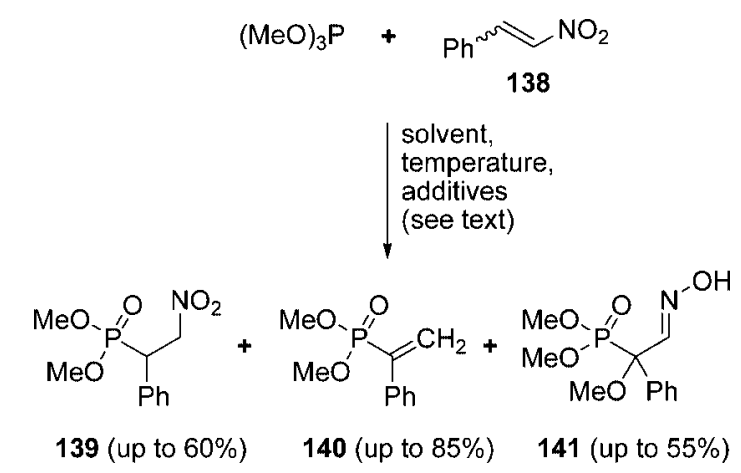

Scheme 32.

reaction that will be treated in the section about phosphorus containing acceptors).

A thorough investigation (23 examples) of the addition of $O$-alkyl aryl phosphinites to $\beta$-nitrostyrenes was reported by $\mathrm{Li}$ and co-workers (Scheme 33). ${ }^{[75]}$
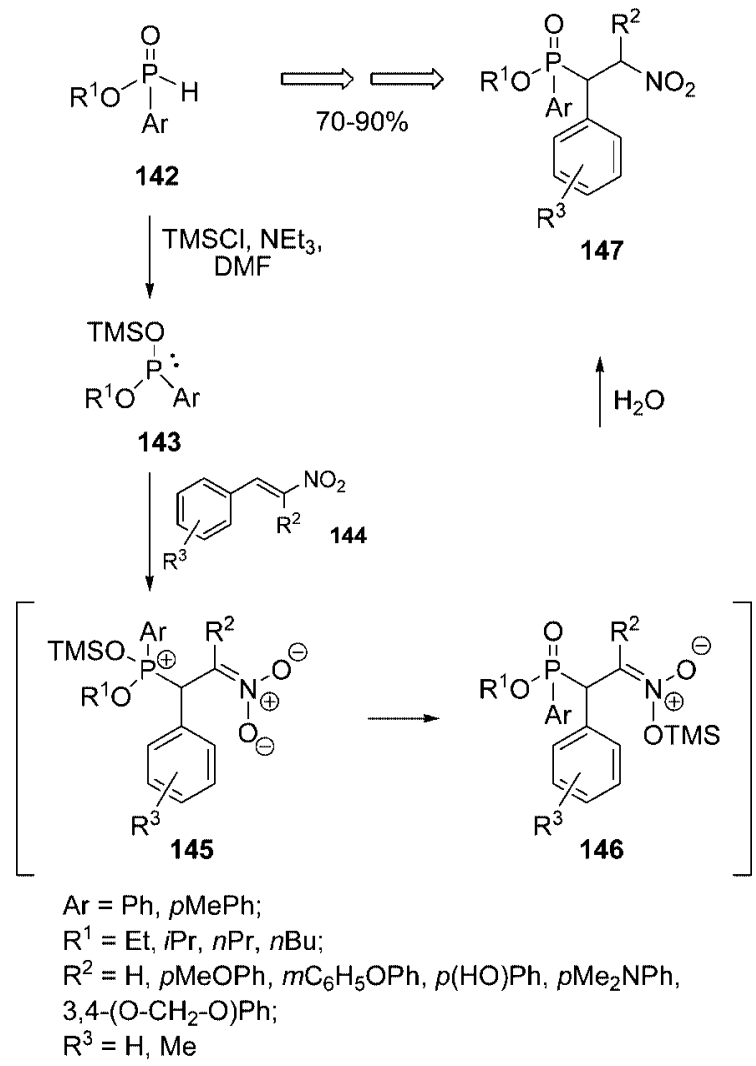

Scheme 33.

A one-pot procedure for the synthesis of ( $\alpha$-aryl- $\beta$-nitroalkyl)phosphinates 147 was developed and a mechanism was proposed proceeding through a Michael addition (143 $+144 \rightarrow 145$ ) followed by an Arbuzov-type rearrangement $(145 \rightarrow \mathbf{1 4 6})$. The products were obtained with yields ranging from 70 to $90 \%$. In this case the reactive species was not the phosphinite 142, but the trivalent phosphorus intermediate 143. The Michael acceptor was introduced to the reaction mixture after the formation of $\mathbf{1 4 3}$. The reaction conditions, solvent and temperature effects were discussed, 
and the stereochemical outcome of the reaction was rationalised using NMR and X-ray data obtained from a crystalline product.

Some of these nitrostyrene acceptors were also employed by Wang and Yuan ${ }^{[76]}$ in addition reactions using dialkyl phosphites for the synthesis of ( $N$-hydroxyindol-3-yl)phosphonates (152) and (2-oxoindol-3-yl)phosphonates (153) besides the normal addition products, (1-aryl-2-nitroalkyl) phosphonates (151) (Scheme 34).

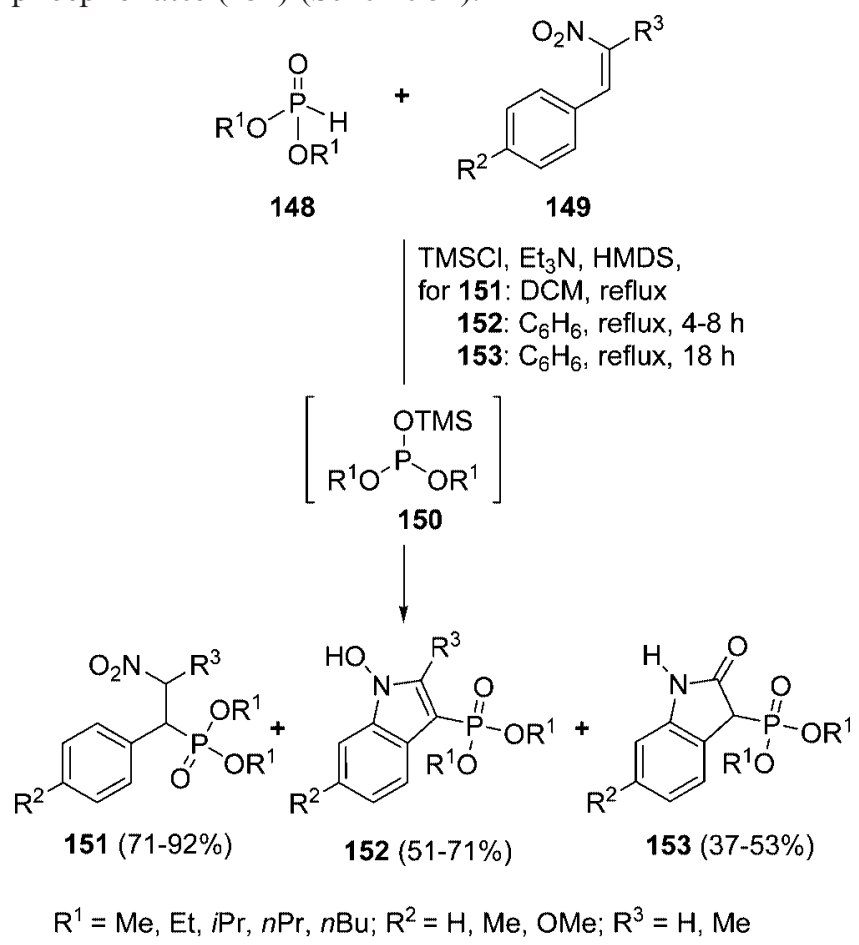

Scheme 34 .

Increasing the quantity of $\mathrm{TMSCl}\left(1-3\right.$ equiv.) and $\mathrm{Et}_{3} \mathrm{~N}$ ( $1-3$ equiv.) and using HMDS (1-2 equiv.) caused the Michael reaction to proceed and the intermediate (equivalent to $\mathbf{1 4 5}$ Scheme 33) to react further with either TMSCl or $\mathrm{Et}_{3} \mathrm{~N}$. Variation of the ratio of the reagents allowed the different products to be obtained selectively. An overall mechanism was proposed involving $\mathrm{Et}_{3} \mathrm{~N}$ and/or TMSCl as the reacting species allowing the reaction to proceed beyond the initial addition product.

Petrov and co-workers ${ }^{[77]}$ carried out a variety of Michael additions to the nitroalkenes $\mathbf{1 5 5}$ and 157 (giving 156 and 158, respectively) and studied the possibilities of derivatising some of them (Scheme 35).

Reacting the nitroalkylphosphane oxides 158 with phosphoric acid at $130{ }^{\circ} \mathrm{C}$ afforded the corresponding carboxylic acids $\mathbf{1 5 9}$ (a transformation that is referred to as the Meyer reaction) and heating over $180^{\circ} \mathrm{C}$ resulted in a subsequent decarboxylation to give the alkylphosphane oxides $\mathbf{1 6 0}$.

Yamashita and co-workers demonstrated the conversion of primary nitro functionalities into aldehydes in the presence of phosphane oxides ${ }^{[78 \mathrm{a}]}$ or phosphonate groups ${ }^{[78 b]}$ under very mild conditions (Scheme 36).

The Michael adducts 162 were first treated with sodium methoxide to generate $\mathbf{1 6 3}$. Their ozonolysis at low tem-
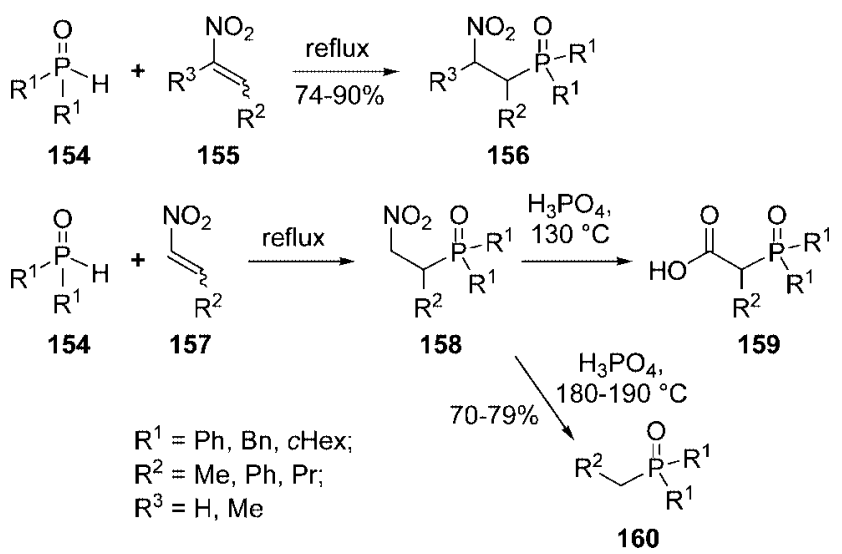

Scheme 35 .

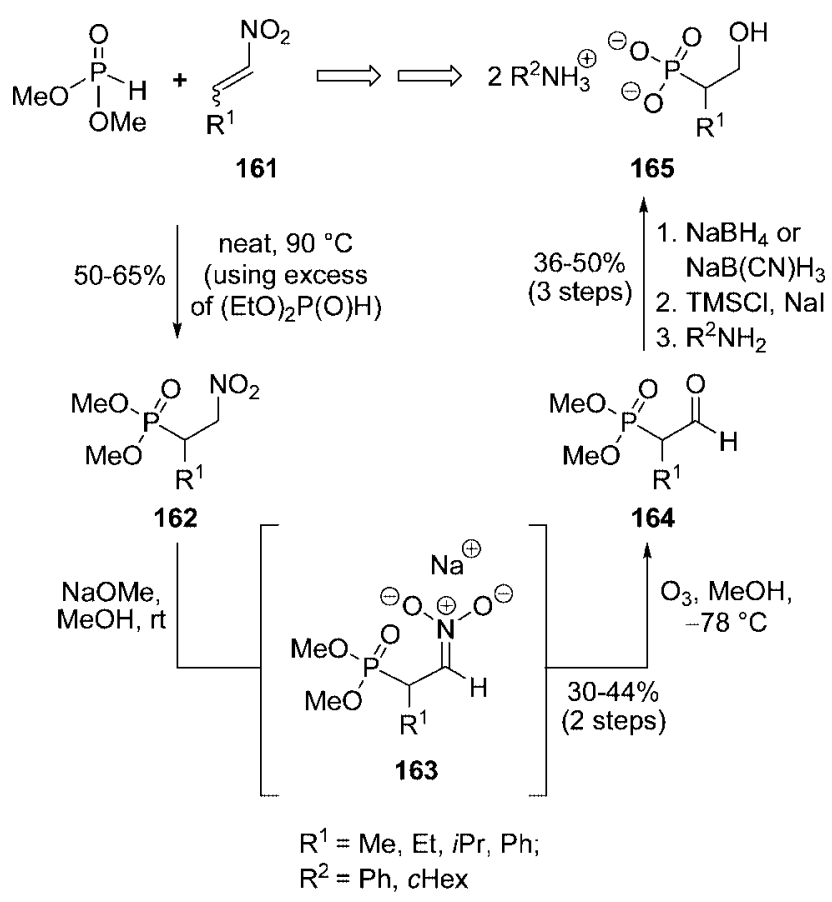

Scheme 36

perature yielded the (1-formylalkyl)phosphonates 164 in moderate yield. To show the usefulness of the latter compounds they were transformed to the ammonium phosphonates 165 in three steps. $\beta$-Nitrophosphonates, phosphinates and phosphane oxides can also be made to eliminate nitrous acid giving the corresponding $\alpha, \beta$-unsaturated phosphorus compounds. ${ }^{[79]}$

The examples so far, simply described the synthesis of racemic products. Asymmetric versions of these reactions mainly deal with substrate-controlled diastereoselective additions. In this field, sugar derived substrates have been studied most frequently. The issue of auxiliary-controlled Michael additions on the other hand comprises only a very few examples (vide infra).

Tronchet and co-workers ${ }^{[80]}$ described the synthesis of novel types of nitrosugars with potentially reactive functionality in the vicinity of the nitro group. Starting from the aldehydosugar 166, the E-configured Michael acceptor 167 
was obtained in two steps (nitro aldol reaction and dehydratisation). However, trimethyl phosphite added to this alkene to yield the phosphorylated sugar 168 in only $22 \%$ yield (Scheme 37).

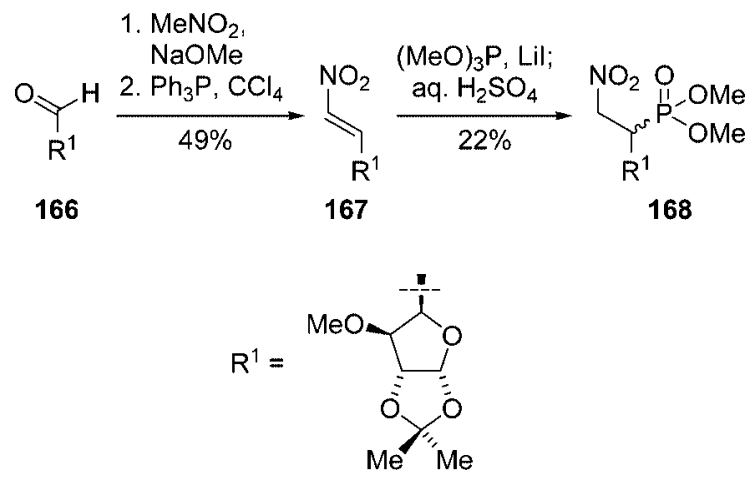

Scheme 37.

Yamashita and co-workers ${ }^{[81]}$ looked at the diastereoselectivity of the addition of various phosphorus nucleophiles 170 to the $Z$-configured nitroalkene acceptors 169 bearing the same sugar residue as $\mathbf{1 6 7}$ (cf. Scheme 37). L-Idose derivatives were the main reaction products, and it was argued that the steric hindrance caused by $\mathrm{R}^{1}-\mathrm{R}^{3}$ and the assumption that this nucleophilic addition followed Cram's rule were responsible for this observation. In accordance with this, the percentage of L-idose derivatives increased with the steric bulk of $\mathrm{R}^{1}-\mathrm{R}^{3}$. No reaction was observed with dimesitylphosphane (170: $\mathrm{R}^{2}=\mathrm{R}^{3}=$ mesityl; $\mathrm{X}=$ lone pair; Scheme 38).
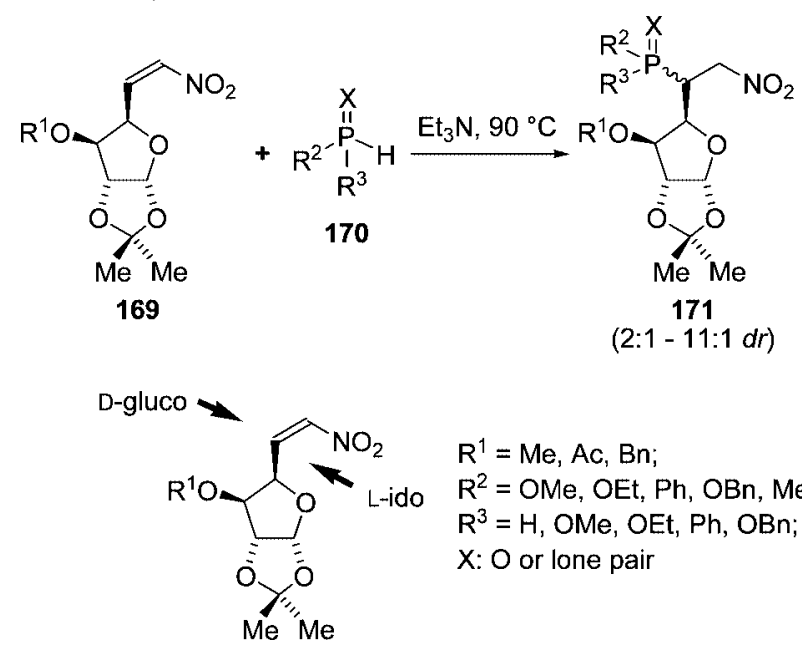

$\mathrm{R}^{1}=\mathrm{Me}, \mathrm{Ac}, \mathrm{Bn} ;$

$\mathrm{R}^{2}=\mathrm{OMe}, \mathrm{OEt}, \mathrm{Ph}, \mathrm{OBn}, \mathrm{Mes}$;

$\mathrm{R}^{3}=\mathrm{H}, \mathrm{OMe}, \mathrm{OEt}, \mathrm{Ph}, \mathrm{OBn}$;

$\mathrm{X}: \mathrm{O}$ or lone pair

Scheme 38.

Yamamoto and co-workers ${ }^{[82]}$ carried out a systematic study on the stereoselectivity of the addition of dimethyl phosphonate to the $E$-configured nitro enofuranoses 172af (Scheme 39).

Two different methods (see Scheme 39) were investigated and it was found that both gave a complementary stereochemical outcome. Whereas method A gave predominantly the $R$ stereoisomer, the opposite was true in the case of method B. Only the acceptors $\mathbf{1 7 2 e}$ and $\mathbf{1 7 2 f}$ seemed to be particular in some way: In the case of $\mathbf{1 7 2 f}$ and method A
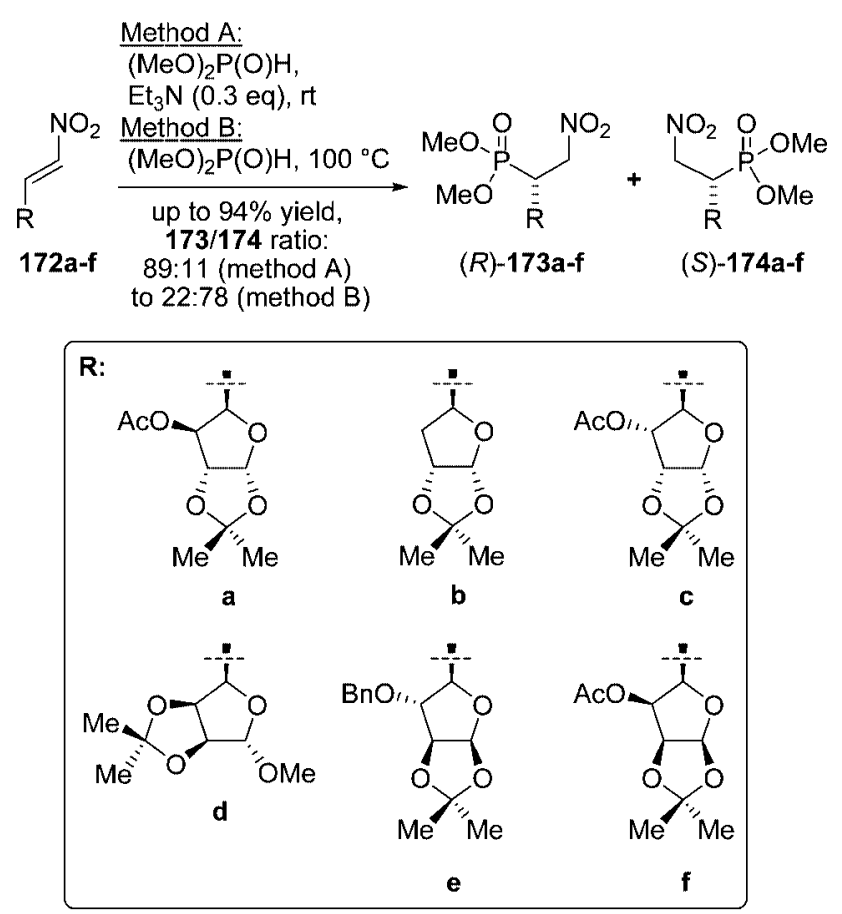

Scheme 39.

only decomposition of the starting material was observed, whereas method B did not give any adduct. In the case of 172e an addition was only observed with method $\mathrm{A}$ but in very low yield $(8 \%)$. In all other cases yields were good to very good (55 to $94 \%$ ) and diastereoselectivites varied from 66:34 to 89:11 in favour of $\mathbf{1 7 3}$ (method A) and from 52:48 to $78: 22$ in favour of $\mathbf{1 7 4}$ (method B). The stereoselectivity was explained by a different conformation being adopted by the nitro olefin in dependence of the method used (Figure 1).
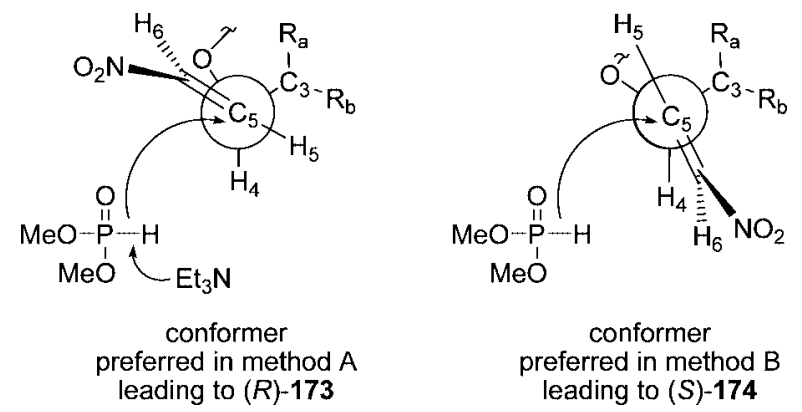

Figure 1. Different stereochemical outcomes in the $P$-Michael additions to nitroolefins (cf. Scheme 38).

Such $P$-Michael additions to nitroalkenes bearing a sugar moiety were used mainly by Yamamoto and coworkers ${ }^{[83]}$ for the synthesis of sugar analogues, which possess a phosphorus atom in place of oxygen in the hemiacetal ring.

Starting from phosphorus trichloride and (-)-menthol (175a) or (-)-di- $O$-isopropylidene-1,2:5,6- $\alpha$-D-glycofuranose (175b), Kolodiazhnyi and co-workers ${ }^{[84]}$ have synthesised the $C_{3}$-symmetric phosphites 176a,b (Scheme 40). Using the former in the acid-catalysed Michael addition to $\beta$-nitrosty- 
rene (138), they obtained the respective adduct 177 as a 3:1mixture of diastereomers. Recrystallisation from aqueous acetone yielded the major isomer diastereomerically pure in $50 \%$ yield.

$$
\underset{175 a, b}{3 \mathrm{R}^{*} \cdot \mathrm{OH}+\mathrm{PCl}_{3} \stackrel{\mathrm{Et}_{3} \mathrm{~N}}{\longrightarrow}} \begin{aligned}
& \mathrm{P}\left(\mathrm{OR}^{*}\right)_{3} \\
& 176 \mathbf{a}, \mathbf{b}
\end{aligned}
$$<smiles>CC(C)C(C)C1CC[C@@H](C)C[C@H]1O</smiles><smiles>CC1(C)OCC([C@H]2O[C@@H]3OC(C)(C)O[C@@H]3[C@H](O)[C@H]2O)O1</smiles>

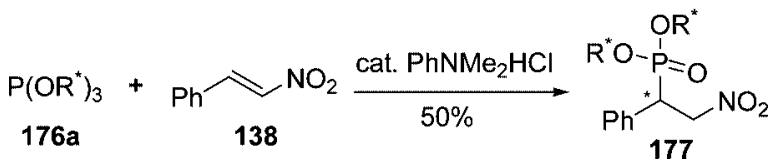

Scheme 40.

At about the same time, our group ${ }^{[85]}$ reported on a new asymmetric $P$-Michael addition to aromatic $\beta$-nitroalkenes. For this, the phosphorus nucleophile $\mathbf{6 1}$ was easily synthesised from TADDOL (178) and phosphorus trichloride in excellent yield (Scheme 41). The diethylzinc-mediated Michael addition proved to be high yielding (86-91\%) and highly stereoselective (84-91\% de). Moreover, diasteromerically pure products could be obtained easily by recystallisation or preparative HPLC. The adducts $\mathbf{1 8 0}$ could finally

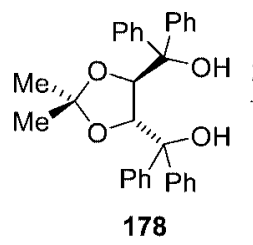

1. $\mathrm{PCl}_{3}, \mathrm{Et}_{3} \mathrm{~N}$

2. $\mathrm{H}_{2} \mathrm{O}, \mathrm{Et}_{3} \mathrm{~N}$

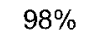

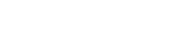

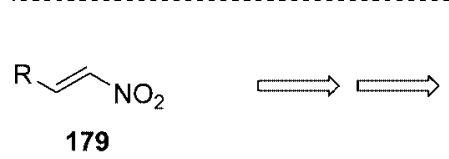

179
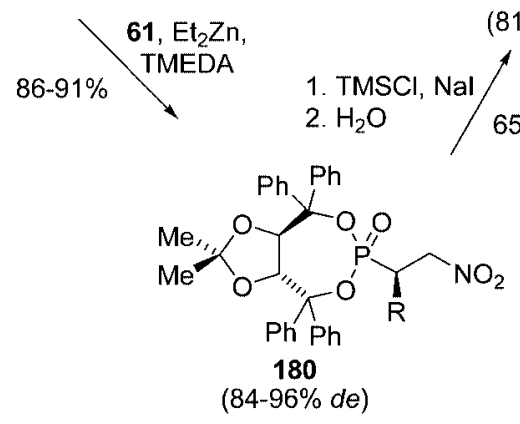

$\mathrm{R}=\mathrm{Ph}, \mathrm{pBiph}, 3,4,5-(\mathrm{MeO})_{3} \mathrm{Ph}, \mathrm{pMePh}, 2-\mathrm{Naphth}, \mathrm{Fc}$ be converted into the phosphonic acids $\mathbf{1 8 1}$ without racemisation.

\section{Olefinic Acceptors Bearing Sulfoxides or Sulfones}

An early investigation on acceptors bearing sulfoxides and/or sulfones goes back to Yamashita and co-workers ${ }^{[86]}$ (Scheme 42).

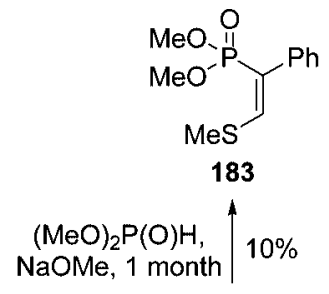<smiles>CS(=O)/C(=C/c1ccccc1)S(C)(=O)=O</smiles>

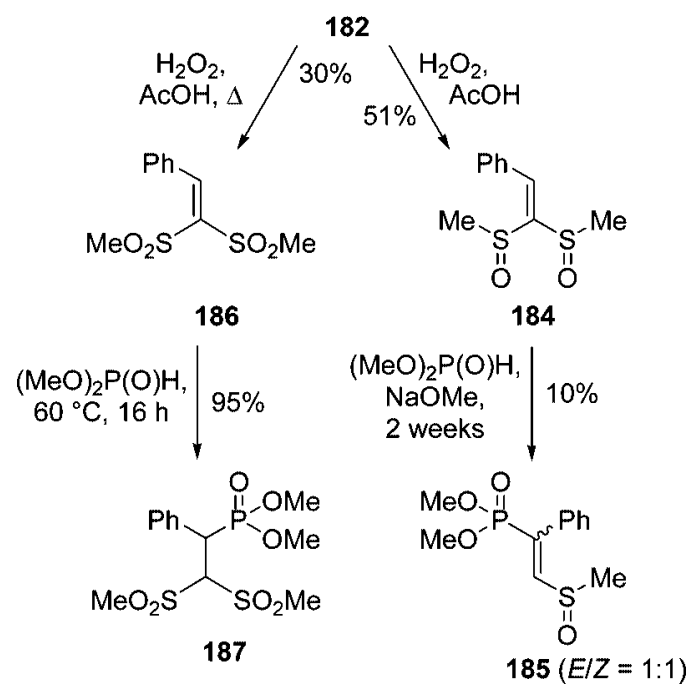

Scheme 42.

Whereas the sulfoxide 182 and the bis(sulfoxide) 184 reacted with dimethyl phosphonate in the presence of sodium methoxide to give the products $\mathbf{1 8 3}$ and $\mathbf{1 8 5}$ in very low yield $(10 \%)$ even after an extended period of time, the bis(sulfone) 186 did not need base-catalysis to yield 187 in excellent yield after only 16 hours (the initial adducts could not be isolated in the case of $\mathbf{1 8 3}$ and $\mathbf{1 8 5}$, since an elimination of a sulfinyl group prevailed due to the basic reaction conditions). Bearing in mind the different reaction times needed for $\mathbf{1 8 3}$ and $\mathbf{1 8 5}$, the following reactivity order seems to be resonable: $-\mathrm{SMe}<-\mathrm{SOMe}<<-\mathrm{SO}_{2} \mathrm{Me}$.

The reaction of bromovinyl aryl sulfones with phosphorus triamides was investigated by Berdnikov and coworkers. ${ }^{[87]}$ It was shown that the halogen atom or both the halogen and the sulfonyl group could be eliminated depending on the reaction conditions (Scheme 43). 


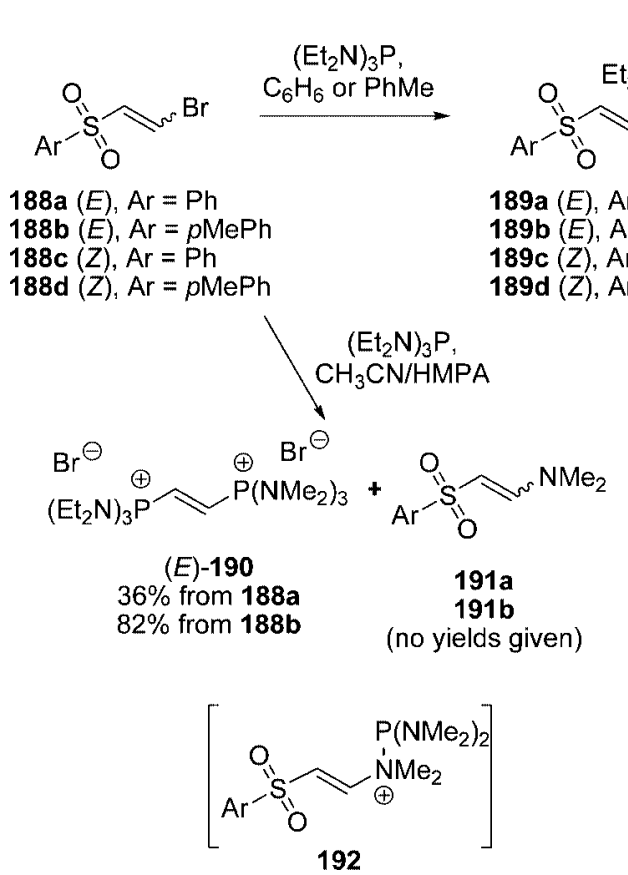

Scheme 43.

Reacting the unsaturated sulfones $\mathbf{1 8 8 a}-\mathbf{d}$ in benzene or toluene with $\left(\mathrm{Et}_{2} \mathrm{~N}\right)_{3} \mathrm{P}$ furnished the salts 189a-d in average to good yields. Changing the solvent to acetonitrile had a pronounced effect on the course of the reaction. Now, the expected $P$-Michael product was not obtained any more. Instead, the diphosphonium salt $(E)-\mathbf{1 9 0}$ was formed along with the amines 191a and 191b. It was suggested that 191a,b resulted from the attack of one nitrogen atom of hexamethylphosphorus triamide leading to the intermediate 192, followed by an elimination of tetramethylphosphoryldiamido bromide.

\section{Olefinic Acceptors Bearing Phosphonates or Phosphane Oxides}

As mentioned above (cf. Scheme 32), Vafina and coworkers ${ }^{[74}$ observed the addition of trimethyl phosphite to the vinylphosphonate 140, which had been formed by the elimination of nitrous acid from the "expected" $P$-Michael adduct 139 (Scheme 44).

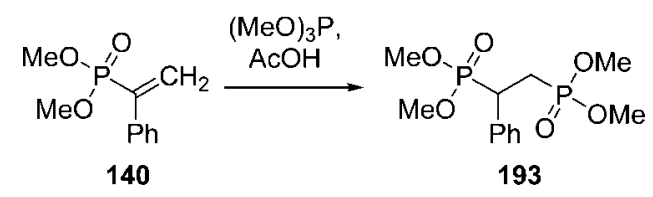

Scheme 44.

In order to study the structure of trans-cyclohexanediphosphonic acid (196), Hägele and co-workers ${ }^{[88]}$ performed a $P$-Michael addition to the unsaturated phosphonate 194. The diphosphonate 195 was obtained in good yield and subsequent acidic hydrolysis led to the desired compound 196 (Scheme 45).

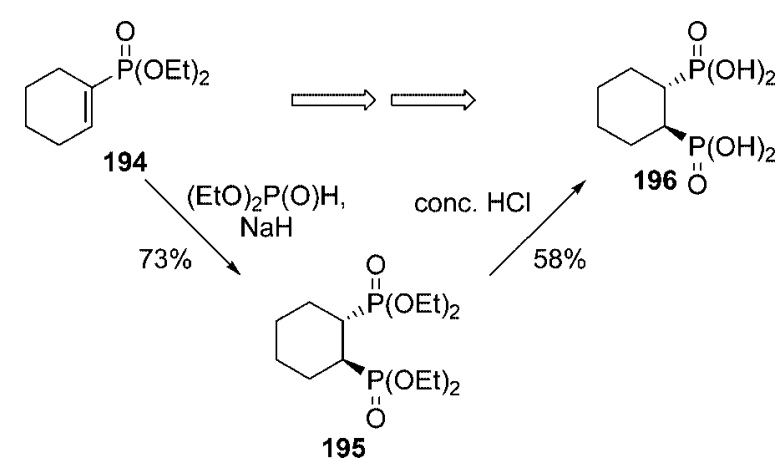

Scheme 45.

The diastereoselective synthesis of the tetrahydrophosphinine oxides 198 was reported by Keglevich and coworkers. ${ }^{[89]}$ Five compounds were synthesised, and their conformations were determined by NMR and computational methods (Scheme 46).

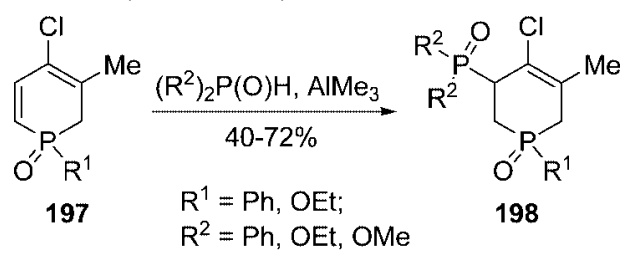

Scheme 46.

\section{Alkynic Acceptors}

The scope of the acceptors used in phospha-Michael additions is very broad and includes substrates containing a triple bond. A new method for the synthesis of vinylphosphonium salts was reported by Larpent and co-workers. ${ }^{[00]}$ The reactions were performed as part of a study on nucleophilic additions of water soluble phosphanes (e. g. 199 and 200) to the activated alkynes 201 . The reactions were carried out in water or deuterium oxide, the latter leading to the deuterated products (Scheme 47).
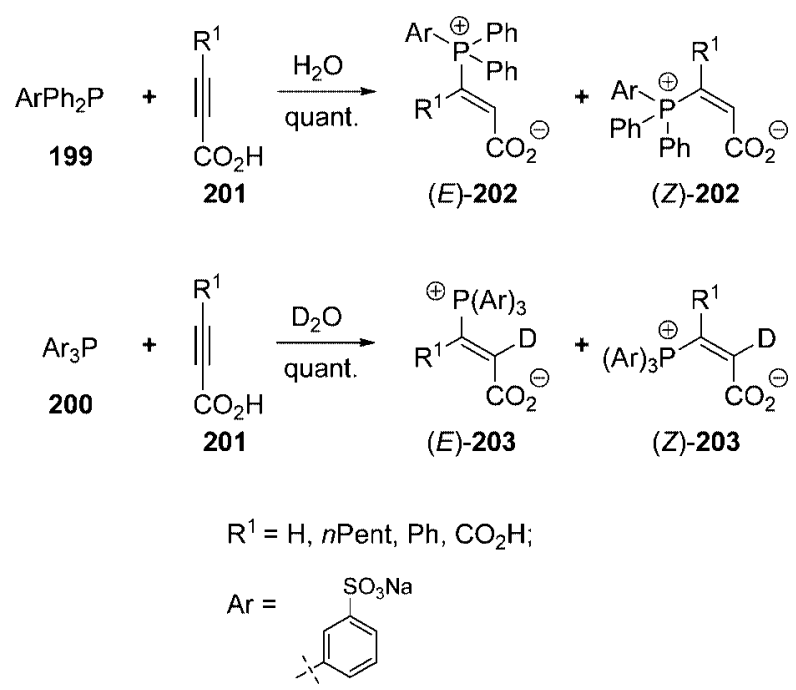

Scheme 47. 
The salts $\mathbf{2 0 2}$ were isolated quantitatively, with the $Z$ isomer being the major product. However, in $\mathrm{D}_{2} \mathrm{O}$, selective deuteration at the $\beta$-position occurred to give 203. Hydrophobic alkynes could also be made to react with the aforementioned phosphanes in a biphasic system in the absence of a phase-transfer agent and the actual outcome was found to be $\mathrm{pH}$ dependent with phosphane oxides being formed in neutral solution and phosphonium salts in $1 \mathrm{~N} \mathrm{HCl}$. Subsequent studies included similar reactions with the water insoluble triphenylphosphane in reverse microemulsions. ${ }^{[90 b]}$

A significant amount of research was carried out by Burdaga and co-workers ${ }^{[91]}$ employing dimethyl acetylenedicarboxylate (30) as the electrophile. They started by looking at the synthesis of vinylphosphoranes (Scheme 48).

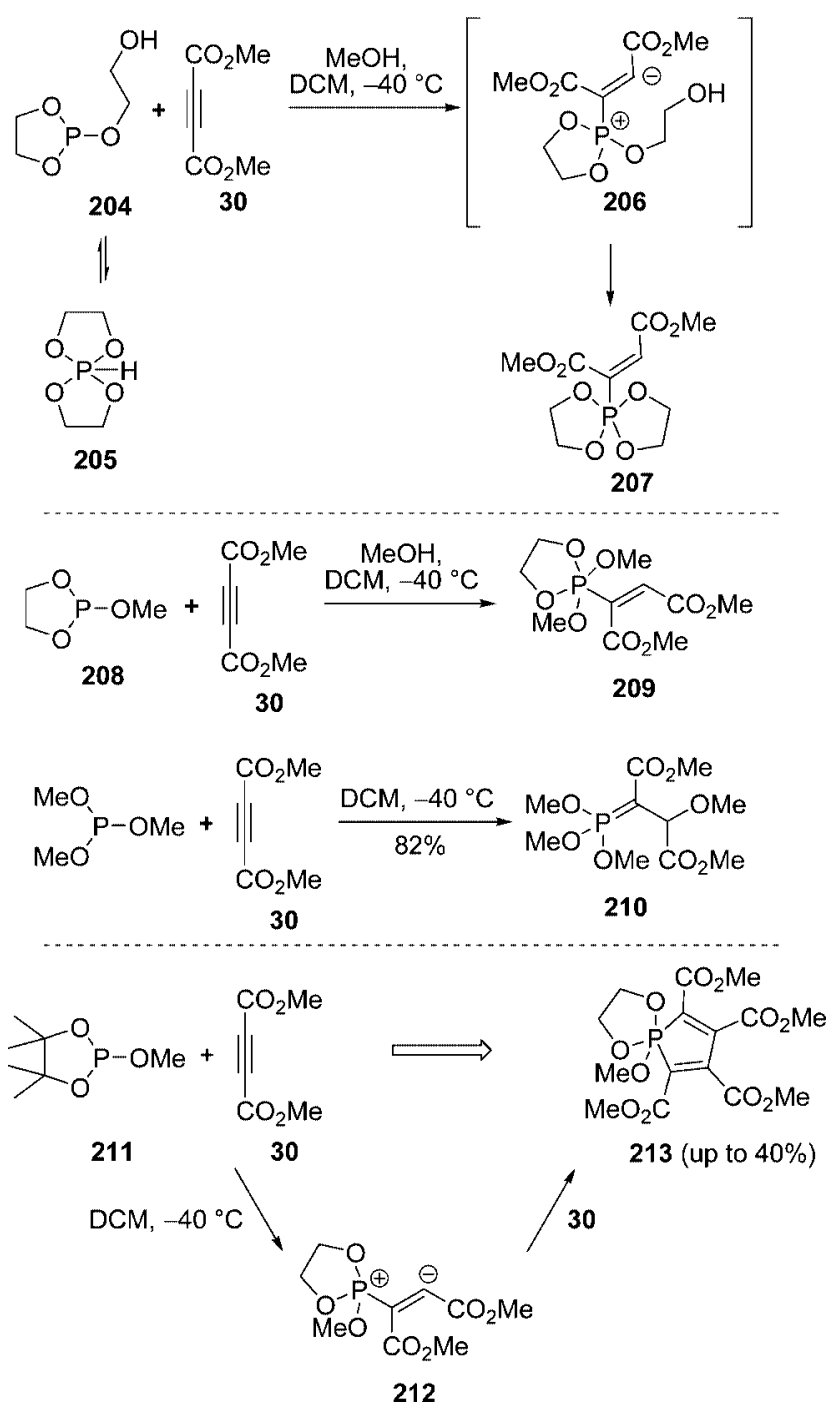

Scheme 48 .

The spirophosphorane $\mathbf{2 0 5}$ was shown to react in its monocyclic form 204 with the acetylenic acceptor 30 and to proceed via the intermediate $\mathbf{2 0 6}$ before giving the vinylspirophosphorane 207. This result was encouraging enough to test other monocyclic phosphoranes such as the methoxyphosphorane $\mathbf{2 0 8}$ in the presence of methanol, which led to the formation of the vinylphosphorane 209. It was shown that the nature of the phosphorus species influenced the course of the reaction and that an ylide such as $\mathbf{2 1 0}$ could also be obtained. Furthermore, some of the ylides could be isomerised back to the vinylphosphorane. In the absence of any trapping agent, the intermediate $\mathbf{2 1 2}$ could react with a second acetylenic moiety and form the unsaturated cyclic phosphole 213 as a byproduct in up to $40 \%$ yield. In a later study methanol was exchanged for various heteroatom-containing trapping compounds. ${ }^{[92]}$

In 1983, Kostyanovskii and co-workers ${ }^{[93]}$ investigated the chemistry of propionitrile (215). Amongst the numerous reactions undertaken three examples represented $P$-Michael additions (Scheme 49).

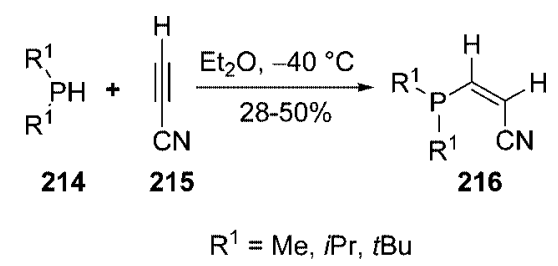

Scheme 49

Only the $Z$ isomer was obtained based on the coupling constants of the ethylenic hydrogen atoms.

More recently, Arbuzova and co-workers ${ }^{[94]}$ undertook the phosphorylation of other cyanoacetylenes. Preferential formation of the $Z$ isomer was also observed and explained with the trans-mode of nucleophilic addition to activated acetylenes ${ }^{[95]}$ as well as for steric reasons (Scheme 50).

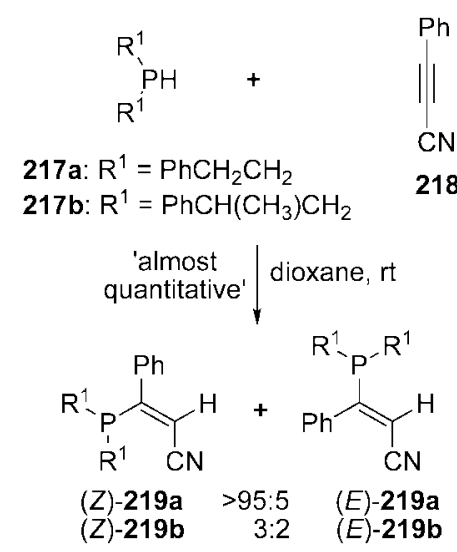

Scheme 50

The reaction of $217 \mathbf{a}, \mathbf{b}$ led to the acrylonitriles $219 \mathbf{a}, \mathbf{b}$ in almost quantitative yields. The ratio of $E / Z$ isomers was determined by NMR spectroscopy. Following the reaction of 219a by ESR revealed the presence of an unpaired electron in the reaction medium. When the reaction was repeated in the presence of up to $3 \mathrm{wt} .-\%$ hydroquinone, no influence on the outcome, on the rate or product yield was observed, confirming a nucleophilic addition mechanism rather than a radical process. The study was later extended to incorporate other primary and secondary phosphanes. ${ }^{[96]}$ 


\section{Conclusion}

The $P$-Michael addition is definitely one of the most versatile tools for the formation of $\mathrm{P}-\mathrm{C}$ bonds. Depending on both the acceptor and the nucleophile, many different reaction pathways are accessible and products with numerous substitution patterns can be generated. Highly functionalised and valuable buildings blocks are being obtained in only one or two steps.

However, the very small number of asymmetric variants also reveals the necessity for further developments in this area.

\section{Acknowledgments}

Our work was supported by the Fonds der Chemischen Industrie, the Deutsche Forschungsgemeinschaft (SFB, 380, Leibniz-Preis), the Max Planck Gesellschaft and the Alexander von Humboldt Stiftung (Max-Planck-Forschungspreis). We thank the Degussa AG, BASF AG, Bayer AG, Wacker Chemie and the former Hoechst AG for the donation of chemicals.

[1] F. Palacios, C. Alonso, J. M. de los Santos, Chem. Rev. 2005, 105, 899-931, and references cited therein.

[2] a) H. Seto, T. Kuzuyama, Nat. Prod. Rep. 1999, 16, 589-596; b) S. C. Fields, Tetrahedron 1999, 55, 12237-12273.

[3] A. N. Pudovik, I. V. Konovalova, Synthesis 1979, 81-96.

[4] a) M. Tanaka, Top. Curr. Chem. 2004, 232, 25-54; b) F. Alonso, I. P. Beletskaya, M. Yus, Chem. Rev. 2004, 104, 3079-3159.

[5] S. Marque, P. Tordo, Top. Curr. Chem. 2005, 250, 43-76.

[6] a) V. I. Galkin, Y. V. Bakhtiyarova, N. A. Polezhaeva, R. A. Shaikhutdinov, V. V. Klochkov, R. A. Cherkasov, Russ. J. Gen. Chem. 1998, 68, 1052-1056; b) V. I. Galkin, Y. V. Bakhtiyarova, N. A. Polezhaeva, I. V. Galkina, R. A. Cherkasov, D. B. Krivolapov, A. T. Gubaidullin, I. A. Litvinov, Russ. J. Gen. Chem. 2002, 72, 376-383; c) V. I. Galkin, Y. V. Bakhtiyarova, N. A. Polezhaeva, I. V. Galkina, R. A. Cherkasov, D. B. Krivolapov, A. T. Gubaidullin, I. A. Litvinov, Russ. J. Gen. Chem. 2002, 72, 384-389.

[7] For the addition of triphenylphosphane $m$-monosulfonate and triphenylphosphane $m$-trisulfonate to $\alpha, \beta$-unsaturated acids and other acceptors, see; a) C. Larpent, H. Patin, Tetrahedron 1988, 44, 6107-6118; b) A. Bényei, J. N. W. Stafford, Á. Kathó, D. J. Darensbourg, F. Joó, J. Mol. Catal. 1993, 84, 157-163.

[8] H.-J. Cristau, J.-P. Vors, H. Christol, Synthesis 1979, 538-541.

[9] As shown in Scheme $1, \mathrm{PPh}_{3}$ adds to acrylic acid spontaneously. This reaction was also performed using $\mathrm{HBr}$ to trap the betain: H. Hoffmann, Chem. Ber. 1961, 94, 1331-1336.

[10] H.-J. Cristau, J.-P. Vors, H. Christol, Tetrahedron Lett. 1979, 20, 2377-2380.

[11] H. Ohmori, T. Takanami, H. Shimada, M. Masui, Chem. Pharm. Bull. 1987, 35, 2558-2560.

[12] D. A. Evans, K. M. Hurst, J. M. Takacs, J. Am. Chem. Soc. 1978, 100, 3467-3477.

[13] a) A. P. Kozikowski, S. H. Jung, J. Org. Chem. 1986, 51, 34003402; b) A. P. Kozikowski, S. H. Jung, Tetrahedron Lett. 1986, 27, 3227-3230.

[14] According to Evans and co-workers (ref. ${ }^{[12]}$ ), the application of $\mathrm{Ph}_{3} \mathrm{P} / \mathrm{Me}_{3} \mathrm{SiCl}$ yields the corresponding silylenol phosphonium salts only in the case of $\alpha, \beta$-unsaturated aldehydes and ketones lacking a $\beta$-substituent. The use of silyl triflates seems to overcome this limitation (see ref. ${ }^{[13]}$ ).

[15] S. Kim, P. H. Lee, Tetrahedron Lett. 1988, 29, 5413-5416.

[16] See for example: a) A. N. Pudovik, A. A. Sobanov, I. V. Bakhtiyarova, M. G. Zimin, Zh. Obshch. Khim. 1983, 53, 2456-2464; b) E. Öhler, E. Zbiral, Liebigs Ann. Chem. 1991, 229-236.
[17] A. A. Sobanov, I. V. Bakhtiyarova, M. G. Zimin, A. N. Pudovik, Zh. Obshch. Khim. 1986, 56, 711.

[18] A. Yu. Platonov, A. A. Sivakov, V. N. Christokletov, E. D. Maiorova, Russ. J. Gen. Chem. 1999, 69, 493-494.

[19] The following references list some nice examples directed towards the synthesis of aminophosphonic and aminophosphinic acids. Addition to unsaturated nitriles: a) W. Froestl, S. J. Mickel, R. G. Hall, G. von Sprecher, D. Strub, P. A. Baumann, F. Brugger, C. Gentsch, J. Jaeckel, H.-R. Olpe, G. Rihs, A. Vassout, P. C. Waldmeier, H. Bittiger, J. Med. Chem. 1995 , 38, 3297-3312; b) W. Froestl, S. J. Mickel, G. von Sprecher, P. J. Diel, R. G. Hall, L. Maier, D. Strub, V. Melillo, P. A. Baumann, R. Bernasconi, C. Gentsch, K. Hauser, J. Jaeckel, G. Karlsson, K. Klebs, L. Maître, C. Marescaux, M. F. Pozza, H.R. Olpe, P. C. Waldmeier, H. Bittiger, J. Med. Chem. 1995, 38, 3313-3331; addition to unsaturated amides: c) J. Barycki, P. Mastalerz, M. Soroka, Tetrahedron Lett. 1970, 11, 3147-3150; addition to unsaturated esters: d) C. Wasielewski, M. Topolski, L. Dembrowski, J. Prakt. Chem. 1989, 331, 507-510.

[20] D. Sperandio, A. R. Gangloff, J. Litvak, R. Goldsmith, J. M. Hataye, V. R. Wang, E. J. Shelton, K. Elrod, J. W. Janc, J. M. Clark, K. Rice, S. Weinheimer, K.-S. Yeung, N. A. Meanwell, D. Hernandez, A. J. Staab, B. L. Venables, J. R. Spencer, Bioorg. Med. Chem. Lett. 2002, 12, 3129-3133.

[21] The deprotonation of a $\mathrm{R}_{2} \mathrm{P}(\mathrm{O}) \mathrm{H}$ compound is one way to generate the $\mathrm{R}_{2} \mathrm{P}(\mathrm{O}) \mathrm{M}$ fragment. An alternative starts from the chloride $\mathrm{Ph}_{2} \mathrm{P}(\mathrm{O}) \mathrm{Cl}$ which is reacted with $\mathrm{Cp}_{2} \mathrm{Sm}$ to yield $\mathrm{Ph}_{2} \mathrm{P}(\mathrm{O}) \mathrm{SmCp}_{2}$ : F. Dallemer, J. Collin, H. B. Kagan, Applied Organomet. Chem. 1995, 9, 431-435.

[22] D. Simoni, F. P. Invidiata, M. Manferdini, I. Lampronti, R. Rondanin, M. Roberti, G. P. Pollini, Tetrahedron Lett. 1998, 39, 7615-7618.

[23] R. A. Stockland, Jr., R. I. Taylor, L. E. Thompson, P. B. Patel, Org. Lett. 2005, 7, 851-853.

[24] C. Laurenco, R. Burgada, Tetrahedron 1976, 32, 2253-2255.

[25] R. Burgada, A. Mohri, Y. El Khoshnieh, C. R. Acad. Sci. Paris, Ser. C 1979, 165-167.

[26] R. K. Haynes, W. W.-L. Lam, L.-L. Yeung, Tetrahedron Lett. 1996, 37, 4729-4732.

[27] L. Tedeschi, D. Enders, Org. Lett. 2001, 3, 3515-3517.

[28] a) G. Castelot-Deliencourt, X. Pannecoucke, J.-C. Quirion, Tetrahedron Lett. 2001, 42, 1025-1028; b) G. Castelot-Deliencourt, E. Roger, X. Pannecoucke, J.-C. Quirion, Eur. J. Org. Chem. 2001, 3031-3038.

[29] D. Dvořák, D. Šaman, M. Buděšínský, Z. Arnold, Collect. Czech. Chem. Commun. 1987, 52, 2926-2935.

[30] For a similar transformation, using 2-phenyl-1,3-diphenylpropane-1,3-dione as the electrophile, see: L. S. Boulos, R. Shabana, Y. M. Shaker, Heteroat. Chem. 2000, 11, 57-64.

[31] See for example: a) M. R. Mahran, W. M. Abdou, N. M. Abd El-Rahman, M. M. Sidky, Phosphorus, Sulfur Silicon Relat. Elem. 1989, 45, 47-54; b) W. M. Abdou, M. D. Khidre, M. R. Mahran, J. Prakt. Chem. 1990, 332, 1029-1034.

[32] F. Ramirez, J. F. Pilot, O. P. Madan, C. P. Smith, J. Am. Chem. Soc. 1968, 90, 1275-1280.

[33] When reacted with arylmethylenemalonaldehydes $\mathrm{Bu}_{3} \mathrm{P}$ and $\left(\mathrm{Et}_{2} \mathrm{~N}\right)_{3} \mathrm{P}$ give the betain exclusively: D. Dvořák, Z. Arnold, Collect. Czech. Chem. Commun. 1987, 52, 2699-2709.

[34] P. D. Beer, R. C. Edwards, C. D. Hall, J. Chem. Soc., Chem. Commun. 1980, 351-352.

[35] A. K. Bhattacharya, G. Thyagarajan, Chem. Rev. 1981, 81, 415-430.

[36] T. Janecki, R. Bodalski, Synthesis 1990, 799-801.

[37] C. Muthiah, K. Senthil Kumar, J. J. Vittal, K. C. Kumara Swamy, Synlett 2002, 1787-1790.

[38] D. Basavaiah, S. Pandiaraju, Tetrahedron 1996, 52, 2261-2268.

[39] For other studies (not confined to trialkyl phosphites) regarding Michael additions vs. $\mathrm{S}_{\mathrm{N}} 2$ reactions and Michael addition vs. $\mathrm{S}_{\mathrm{N}} 2^{\prime}$ reactions, see: a) H. Düttmann, P. Weyerstahl, Chem. 
Ber. 1979, 112, 3480-3485; b) F. Béji, J. Lebreton, J. Villiéras, H. Amri, Synth. Commun. 2002, 32, 3273-3278.

[40] C. V. Stevens, G. Van Heecke, C. Barbero, K. Patora, N. De Kimpe, R. Verhé, Synlett 2002, 1089-1092.

[41] V. G. Ratner, E. Lork, K. I. Pashkevich, G.-K. Röschenthaler, J. Fluorine Chem. 2000, 102, 73-77.

[42] B. A. Arbuzov, A. V. Fuzhenkova, N. I. Tyryshkin, Zh. Obshch. Khim. 1987, 57, 2197-2200.

[43] B. A. Arbuzov, N. A. Polezhaeva, R. T. Galiaskarova, A. V. Aganov, A. I. Khayarov, Zh. Obshch. Khim. 1982, 52, 1024 1029.

[44] M. Nakano, Y. Okamoto, H. Sakurai, Synthesis 1982, 915.

[45] Y. Okamoto, H. Sakurai, Synthesis 1982, 497-499.

[46] I. Mori, Y. Kimura, T. Nakano, S.-i. Matsunaga, G. Iwasaki, A. Ogawa, K. Hayakawa, Tetrahedron Lett. 1997, 38, 35433546.

[47] B. B. V. Soma Sekhar, W. G. Bentrude, Tetrahedron Lett. 1999, 40, 1087-1090.

[48] E. A. Boyd, A. C. Regan, K. James, Tetrahedron Lett. 1992, 33, 813-816.

[49] The phenyl analogue of $\mathrm{X}$, bis(trimethylsilyl) phenylphosphonite $\left[\mathrm{PhP}(\mathrm{OTMS})_{2}\right]$, undergoes analogous reactions: E. A. Boyd, M. E. K. Boyd, V. M. Loh Jr., Tetrahedron Lett. 1996, 37, 1651-1654.

[50] P. B. Cox, V. M. Loh Jr., C. Monteils, A. D. Baxter, E. A. Boyd, Tetrahedron Lett. 2001, 42, 125-128.

[51] J. Buchardt, M. Meldal, J. Chem. Soc., Perkin Trans. 12000 , 3306-3310.

[52] M. Borloo, X.-Y. Jiao, H. Wójtowicz, P. Rajan, C. Verbruggen, K. Augustyns, A. Haemers, Synthesis 1995, 1074-1076.

[53] J. G. Dingwall, J. Ehrenfreund, R. G. Hall, Tetrahedron 1989, 45, 3787-3808.

[54] X. Liu, E. Hu, X. Tian, A. Mazur, F. H. Ebetino, J. Organomet. Chem. 2002, 646, 212-222.

[55] See for example: a) G. U. Spiegel, O. Stelzer, Chem. Ber. 1990, 123, 989-993; b) H. Brunner, G. Net, Synthesis 1995, 423-426.

[56] G. Knühl, P. Sennhenn, G. Helmchen, J. Chem. Soc., Chem. Commun. 1995, 1845-1846.

[57] T. Minami, Y. Okada, T. Otaguro, S. Tawaraya, T. Furuichi, T. Okauchi, Tetrahedron: Asymmetry 1995, 6, 2469-2474.

[58] For similar Michael additions to acrylic acids and their derivatives, see: a) J. A. van Dorn, N. Meijboom, Phosphorus, Sulfur Silicon Relat. Elem. 1989, 42, 211-222; b) L. Lavenot, M. H. Bortoletto, A. Roucoux, C. Larpent, H. Patin, J. Organomet. Chem. 1996, 509, 9-14.

[59] J. F. G. A. Jansen, B. L. Feringa, Tetrahedron: Asymmetry 1990, 1, 719-720.

[60] G. Fritz, P. Scheer, Chem. Rev. 2000, 100, 3341-3401.

[61] See for example: a) C. Couret, J. Escudie, J. Satge, N. T. Anh, G. Soussan, J. Organomet. Chem. 1975, 91, 11-30; b) M. Reisser, A. Maier, G. Maas, Synlett 2002, 1459-1462.

[62] J. Holz, A. Monsees, H. Jiao, J. You, I. V. Komarov, C. Fischer, K. Drauz, A. Börner, J. Org. Chem. 2003, 68, 1701-1707.

[63] For a similar study, dealing with the addition of diphenylphosphane to bromomaleic anhydride, see: J. A. van Doorn, J. H. G. Frijns, N. Meijboom, J. Chem. Soc., Perkin Trans. 2 1990, 479485.

[64] M. Hayashi, Y. Matsuura, Y. Watanabe, Tetrahedron Lett. 2004, 45, 9167-9169.

[65] Similarly, $\mathrm{KO} t \mathrm{Bu}$ catalyzes the addition of phosphanes to styrenes: T. Bunlaksananusorn, P. Knochel, Tetrahedron Lett. 2002, 43, 5817-5819.

[66] M. Hayashi, Y. Matsuura, Y. Watanabe, Tetrahedron Lett. 2005, 46, 5135-5138.

[67] a) J. B. Rampal, G. D. Macdonell, J. P. Edasery, K. D. Berlin, A. Rahman, D. van der Helm, K. M. Pietrusiewicz, J. Org. Chem. 1981, 46, 1156-1165; b) J. B. Rampal, K. D. Berlin, J. P. Edasery, N. Satyamurthy, D. van der Helm, J. Org. Chem. 1981, 46, 1166-1172.
[68] a) Y. G. Bosyakov, D. G. Kim, A. P. Logunov, G. P. Revenko, O. V. Shiganakova, T. I. Rabetskaya, Zh. Obshch. Khim. 1983, 53, 1050-1054; b) Y. G. Bosyakov, N. Y. Kuz'mina, G. P. Revenko, A. P. Logunov, Zh. Obshch. Khim. 1990, 60, 814-820.

[69] For a similar cyclisation, see: B. M. Butin, G. M. Isaeva, K. B. Erzhanov, Zh. Obshch. Khim. 1985, 55, 2690-2694.

[70] a) T. Imamoto, T. Kusumoto, N. Suzuki, K. Sato, J. Am. Chem. Soc. 1985, 107, 5301-5303; b) T. Imamoto, T. Oshiki, T. Onozawa, T. Kusumoto, K. Sato, J. Am. Chem. Soc. 1990, 112, 5244-5252.

[71] a) Y. Gourdel, P. Pellon, L. Toupet, M. Le Corre, Tetrahedron Lett. 1994, 35, 1197-1200; b) P. Pellon, C. Le Goaster, L. Toupet, Tetrahedron Lett. 1996, 37, 4713-4716.

[72] M. Léautey, G. Castelot-Deliencourt, P. Jubault, X. Pannecoucke, J.-C. Quirion, Tetrahedron Lett. 2002, 43, 9237-9240.

[73] R. D. Gareev, A. V. Il'yasov, Y. A. Levin, E. I. Gol'dfarb, V. I. Morozov, I. M. Shermergorn, A. N. Pudovik, Zh. Obshch. Khim. 1982, 52, 1278-1290.

[74] N. N. Vafina, T. A. Zyablikova, A. V. Il'yasov, I. M. Shermergorn, Zh. Obshch. Khim. 1982, 52, 35-40.

[75] Y.-G. Li, Y.-S. Liu, F.-M. Miao, X.-L. Liu, J.-H. Cao, W. Zhou, M.-X. Wen, Phosphorus, Sulfur Silicon Relat. Elem. 1990, 47, $229-242$

[76] G. Wang, C. Yuan, Heteroatom Chem. 1992, 3, 521-527.

[77] K. A. Petrov, V. A. Chauzov, S. V. Agafonov, N. Y. Lebedeva, Zh. Obshch. Khim. 1983, 53, 56-61.

[78] a) M. Yamada, M. Yamashita, Synthesis 1982, 1026-1027; b) M. Yamashita, M. Sugiura, T. Oshikawa, S. Inokawa, Synthesis 1987, 62-64.

[79] M. Yamashita, Y. Tamada, A. Iida, T. Oshikawa, Synthesis 1990, 420-422.

[80] J. M. J. Tronchet, K. D. Pallie, F. Barbalat-Rey, J. Carbohydr. Chem. 1985, 4, 29-52.

[81] M. Yamashita, M. Sugiura, Y. Tamada, T. Oshikawa, J. Clardy, Chem. Lett. 1987, 1407-1408.

[82] T. Hanaya, H. Yamamoto, H. Yamamoto, Bull. Chem. Soc. Jpn. 1992, 65, 1154-1156.

[83] a) H. Yamamoto, T. Hanaya, H. Kawamoto, S. Inokawa, M. Yamashita, M.-A. Armour, T. T. Nakashima, J. Org. Chem. 1985, 50, 3516-3521; b) T. Hanaya, K. Ohmori, H. Yamamoto, M.-A. Armour, A. M. Hogg, Bull. Chem. Soc. Jpn. 1990, 63, 1174-1179; c) T. Hanaya, A. Noguchi, M.-A. Armour, A. M. Hogg, H. Yamamoto, J. Chem. Soc., Perkin Trans. 1 1992, 295301.

[84] O. I. Kolodiazhnyi, S. Sheiko, E. V. Grishkun, Heteroat. Chem. 2000, 11, 138-143.

[85] D. Enders, L. Tedeschi, J. W. Bats, Angew. Chem. 2000, 112, 4774-4776; Angew. Chem. Int. Ed. 2000, 39, 4605-4607.

[86] M. Yamashita, T. Miyano, T. Watabe, H. Inokawa, H. Yoshida, T. Ogata, S. Inokawa, Bull. Chem. Soc. Jpn. 1979, 52, 466-468.

[87] E. A. Berdnikov, V. L. Polushina, F. R. Tantasheva, E. G. Kataev, Zh. Obshch. Khim. 1980, 50, 993-998.

[88] G. Hägele, R. Peters, K. Kreidler, R. Boese, G. Grossmann, F. Steglich, G. Ohms, Phosphorus, Sulfur Silicon Relat. Elem. 1993, 83, 77-80.

[89] G. Keglevich, M. Sipos, T. Imre, K. Ludányi, D. Szieberth, L. Töke, Tetrahedron Lett. 2002, 43, 8515-8518.

[90] a) C. Larpent, G. Meignan, H. Patin, Tetrahedron 1990, 46, 6381-6398; b) C. Larpent, G. Meignan, H. Patin, Tetrahedron Lett. 1991, 32, 2615-2618.

[91] a) R. Burdaga, Y. O. El Khoshnieh, Y. Leroux, Tetrahedron 1985, 41, 1207-1222; b) R. Burdaga, Y. O. El Khoshnieh, Y. Leroux, Tetrahedron 1985, 41, 1223-1232.

[92] B. Ben Jaafar, D. El Manouni, R. Burdaga, Y. Leroux, Phosphorus, Sulfur Silicon Relat. Elem. 1990, 47, 67-92.

[93] R. G. Kostyanovskii, Y. I. El'natanov, Izvestiya Akademii Nauk SSSR, Seriya Khimicheskaya 1983, 11, 2581-2592.

[94] B. A. Trofimov, S. N. Arbuzova, A. G. Mal'kina, N. K. Gusarova, S. F. Malysheva, M. V. Nikitin, T. I. Vakul'skaya, Mendeleev Commun. 1999, 163-164. 
[95] J. Dickstein, S. Miller, in The Chemistry of the Carbon-Carbon Triple Bond; Part 2 (Ed. S. Patai), Wiley, New York, 1978, pp. 813-955.

[96] N. K. Gusarova, S. I. Shaikhudinova, S. N. Arbuzova, T. I. Vakul'skaya, B. G. Sukhov, L. M. Sinegovskaya, M. V. Nikitin,
A. G. Mal'kina, N. A. Chernysheva, B. A. Trofimov, Tetrahedron 2003, 59, 4789-4794. 